\title{
Biomechanical Influence of Cartilage Homeostasis in Health and Disease
}

\author{
D. L. Bader, ${ }^{1}$ D. M. Salter, ${ }^{2}$ and T. T. Chowdhury ${ }^{1}$ \\ ${ }^{1}$ School of Engineering and Materials Science, Queen Mary University of London, London E1 4NS, UK \\ ${ }^{2}$ Department of Pathology, University of Edinburgh, Edinburgh EH4 $2 X U, U K$
}

Correspondence should be addressed to T. T. Chowdhury, t.t.chowdhury@qmul.ac.uk

Received 1 April 2011; Accepted 26 June 2011

Academic Editor: Johanne Martel-Pelletier

Copyright (C) 2011 D. L. Bader et al. This is an open access article distributed under the Creative Commons Attribution License, which permits unrestricted use, distribution, and reproduction in any medium, provided the original work is properly cited.

\begin{abstract}
There is an urgent demand for long term solutions to improve osteoarthritis treatments in the ageing population. There are drugs that control the pain but none that stop the progression of the disease in a safe and efficient way. Increased intervention efforts, augmented by early diagnosis and integrated biophysical therapies are therefore needed. Unfortunately, progress has been hampered due to the wide variety of experimental models which examine the effect of mechanical stimuli and inflammatory mediators on signal transduction pathways. Our understanding of the early mechanopathophysiology is poor, particularly the way in which mechanical stimuli influences cell function and regulates matrix synthesis. This makes it difficult to identify reliable targets and design new therapies. In addition, the effect of mechanical loading on matrix turnover is dependent on the nature of the mechanical stimulus. Accumulating evidence suggests that moderate mechanical loading helps to maintain cartilage integrity with a low turnover of matrix constituents. In contrast, nonphysiological mechanical signals are associated with increased cartilage damage and degenerative changes. This review will discuss the pathways regulated by compressive loading regimes and inflammatory signals in animal and in vitro 3D models. Identification of the chondroprotective pathways will reveal novel targets for osteoarthritis treatments.
\end{abstract}

\section{Introduction}

It is well established that mechanical loading regulates the structure and function of musculoskeletal tissues and helps maintain the functional integrity of articular cartilage and joint homeostasis. The onset and progression of osteoarthritis (OA) involves all the tissues of the joint initiated by multiple risk factors. These include joint instability and/or misalignment, obesity, previous knee injury, muscle weakness, age, and genetics. It is clear that joint tissues are sensitive to the magnitude, duration, and nature of the mechanical stimulus. A range of approaches have, therefore, been developed to examine the effect of mechanical loading on cartilage homeostasis and OA disease progression. However, each approach has limitations which make it difficult to evaluate the physiological relevance of the experimental findings. This review article will examine the role of abnormal joint loading in cartilage destruction and compare the findings to the protective effects of physiological loading in animal and in vitro models. In addition, we will discuss the intracellular mechanisms which mediate the effects of mechanical loading and explore the potential of using controlled exercise therapy in combination with novel agents as an integrated biophysical approach for OA treatments.

\section{Influence of Nonphysiological Mechanical Loading and Cartilage Destruction}

2.1. Joint Overuse and Excessive Mechanical Loading Is Damaging to the Tissue. Cartilage defects in the knees of young or active individuals remain a problem in orthopaedic practice. The clinical symptoms of $\mathrm{OA}$ are joint pain, limitation of range of motion, and joint stiffness. Sports activities involving high intensity and repetitive loads increase the risk of $\mathrm{OA}$ and are most often associated with other injuries such as knee ligament tears, meniscal injuries, patellae fractures, and osteochondral lesions [1-3]. Cartilage degeneration can develop from direct traumas, joint instability 
and misalignment, as a result of altered patterns of load distribution across the joint [4].

Overloading (e.g., traumatic or high intensity) induces morphological, molecular, and mechanical changes in cells and matrix which leads to softening, fibrillation, ulceration, and loss of cartilage [5-7]. These molecular and biomechanical changes have been shown to shift the balance of tissue remodelling in favour of catabolic over anabolic activity in animal models. However, studies which measure the effects of mechanical loading on cartilage due to overuse in human joints are few in number. By contrast, there are a plethora of experimental studies which have examined the effect of overloading in animal and 3D models (Table 1). For example, strenuous exercise in a canine model caused by running either 20 or $40 \mathrm{~km}$ /day for up to 15 weeks reduced proteoglycan content in the superficial zone of cartilage, increased water content, and decreased the concentration of collagen in the load-bearing region $[8,9]$. In rodents, enforced running of mice for $1 \mathrm{~km} /$ day, or a sudden increase in exercise at an older age resulted in more severe cartilage lesions than observed in sedentary controls $[10,11]$.

In vitro studies have identified a critical stress threshold of 15-20 MPa above which cell death and collagen damage was evident due to a single impact load in bovine cartilage explants $[12,13]$. In a separate study, apoptosis occurred at peak stresses as low as $4.5 \mathrm{MPa}$ followed by collagen degradation at 7 to $12 \mathrm{MPa}$ and nitrite accumulation at $20 \mathrm{MPa}$ [14]. However, the source of the tissue tested and nature of the impact load will certainly influence the type and extent of damage [15]. For example, human cartilage was found to be more resistant to damage than bovine tissue following a single impact load of similar magnitude [16]. This may be due to the structural differences between the two tissue types and cartilage thickness or effects of age-accumulated changes observed in samples from older patients. Furthermore, impact damage is inevitably strain rate dependent. Indeed, in a comparative study, low strain rates had no discernable effect on matrix synthesis in bovine cartilage explants, whereas strain rates up to twofold higher decreased the levels of proteoglycans, and hence reduced both compressive and shear stiffness [17]. The damage caused by repeated impact loading was cumulative in nature, initially inducing necrosis, followed by apoptosis and collagen degradation in cartilage explants $[18,19]$. In addition, the application of static load, equivalent to a compressive strain of $50 \%$, decreased the synthesis of both collagen type II and proteoglycans in bovine cartilage explants [20-22]. Taken together, these experimental findings demonstrate that if joints are insufficiently loaded, cartilage metabolism shifts in favour of catabolism, essentially leading to tissue atrophy. Long-term injurious mechanical loading, which represent high levels of peak stress and/or strain rates, induces abnormal compositional changes in cartilage and accelerates breakdown of the extracellular matrix. However, the magnitude of loads reported in vitro may not replicate the in vivo loading environment. This limitation makes it difficult to identify the range of nonphysiological loading modalities that are likely to be encountered in a clinical setting. Accordingly, clinical studies of critical patient populations may provide more appropriate means of evaluating the physiological relevance of mechanical factors on integrated disease pathways and treatments.

\subsection{Reduced Joint Loading and Disuse Leads to Cartilage} Degeneration. Reduced joint loading (e.g., static and immobilisation) leads to atrophy and degeneration of cartilage (Table 1). Indeed, animal studies demonstrate that prolonged joint immobilisation causes cartilage thinning, tissue softening, and reduced proteoglycan content resulting in matrix fibrillation, ulceration, and erosion [23-25]. An inactive lifestyle leads to $\mathrm{OA}$ like changes in a hamster model, as characterised by reduced proteoglycan content, fibrillation, pitting, and fissuring [26]. In clinical studies, patients with fractures and partial or complete immobilisation presented significant temporal changes in cartilage morphology, including reduced thickness in the femorotibial joint compared to the patella [27]. In the absence of joint loading, patients with spinal cord injuries showed progressive thinning of knee cartilage in the absence of normal joint loading at a rate which was higher than that observed in OA $[28,29]$. However, the loss of proteoglycans following shortterm immobilisation in a canine model was largely reversible and remobilisation of the joint led to restoration of matrix [30-32]. This effect may be possible, since the loading condition primarily affects the proteoglycan content and does not irreversibly influence the collagen network. However, if the animal is actively exercised at the time of remobilisation, the integrity of the tissue will be compromised, suggesting that prolonged immobilisation may cause irreversible damage to the tissue [33-35].

\section{Physiological Mechanical Stimuli and Cartilage Homeostasis}

3.1. Moderate Mechanical Loading Plays a Role in Normal Tissue Remodelling. Several investigators have used a range of approaches to examine the effect of moderate exercise in maintaining cartilage homeostasis (Table 2). Indeed, there is sound evidence that individuals engaging in regular activity are less prone to incidence of $\mathrm{OA}$, since frequent dynamic loading in the physiological range will increase cartilage thickness and maintain normal cartilage integrity [36, 37]. There is also evidence that exercise therapy in the form of aerobic and strengthening activities reduced pain and disability, enhances GAG content, and protects against cartilage degeneration in subjects with knee OA [4, 38-41]. However, the protective effect of recreational exercise has been reported to be dependent on a number of risk factors including age, body mass index, history of knee injury, smoking, and education [42-44]. Clinical observations suggest that healthy subjects as well as OA patients, in general, can pursue a high level of physical activity, provided that the activity is not painful and does not predispose to trauma [45]. However, there is still insufficient information which provides useful guidelines on optimal exercise regimen, dosage, or length of intervention, particularly in overweight individuals [46]. It is interesting to note that prospective 


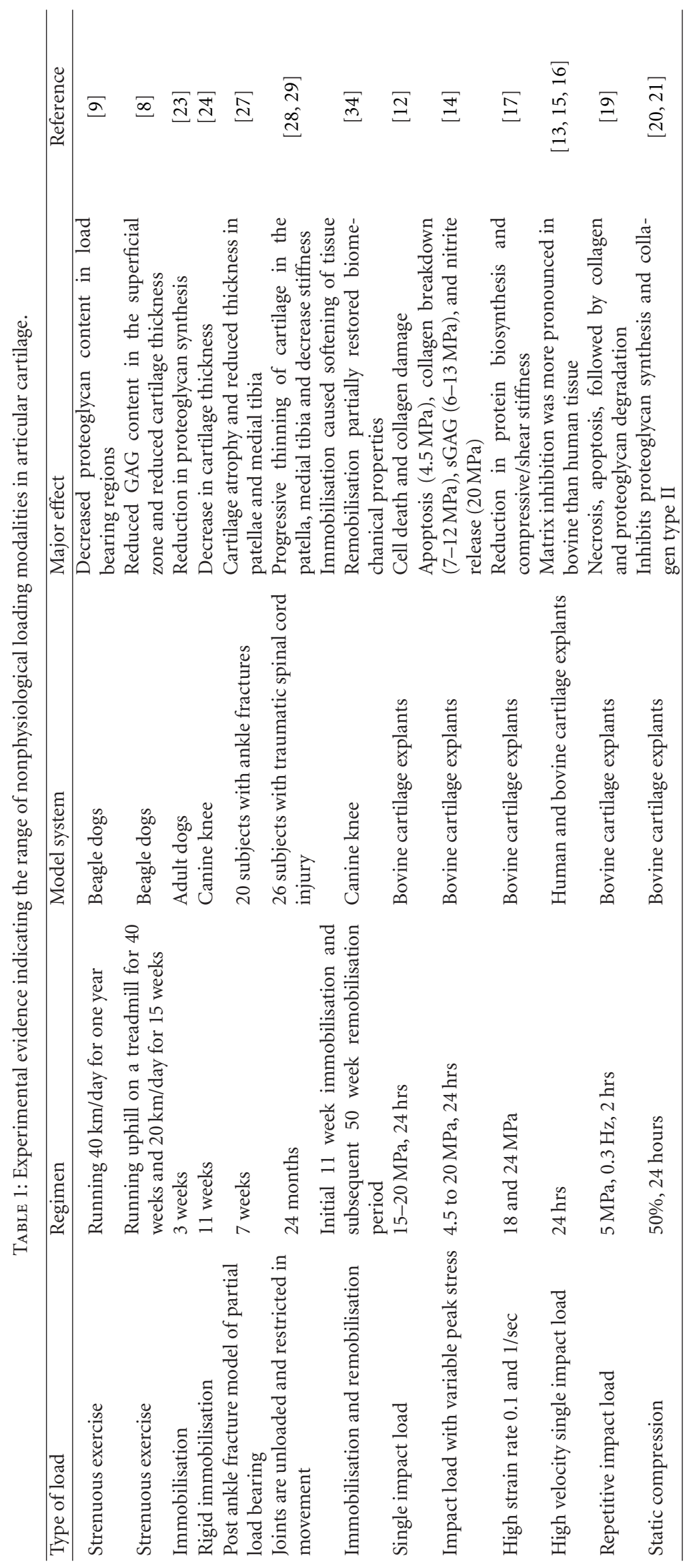




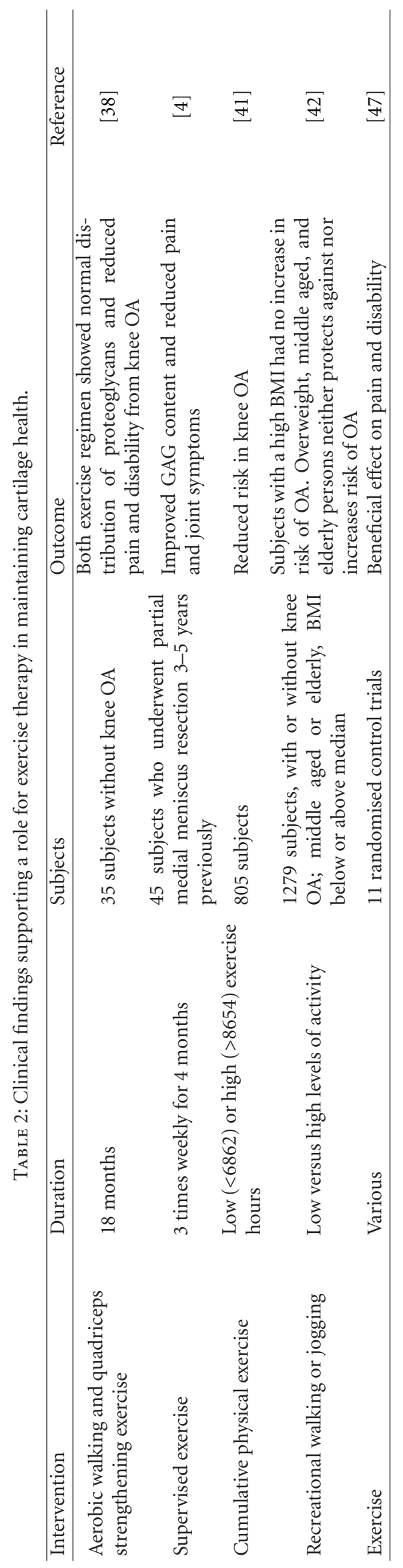


cohort studies which examined the effect of exercise on cartilage properties have reported contradictory results $[4$, 37]. In some patients, the intervention offered pain relief and improvements in physical functioning, but in middleaged or elderly persons without OA, recreational exercise neither protects against nor increases risk of the disease $[42,43,47-49]$. It is inevitable that comparison of findings between clinical studies, is problematic, as they often involve differences in both diagnostic criteria and variable exercise regimens. However, it is certain that understanding the associations between risk factors and benefits of physical activity will provide key information that will have important implications for clinical practice.

In most animal studies, load bearing exercise minimises the development of OA. For example, daily exercise increased proteoglycan content and cartilage thickness in hamster and rodent models $[26,50]$. In dogs, moderate exercise augments GAG content particularly in younger animals $[51,52]$. In hamsters, early joint loading advances the maturation of matrix proteins, improved the integrity of the collagen network and the tissue resistance against OA in older animals [53-56]. In general, exercise and loading of joints within a physiological range appears to have beneficial effects over normal day to day activities characterised by modest movement. The anabolic changes induced by exercise appear to enhance the load bearing properties of cartilage and may help explain how lifelong physical activity protects the joint from OA during later periods in life.

Several in vitro studies have examined the effect of physiological mechanical loading on chondrocyte function and matrix synthesis (Table 3). Indeed, stretching of cells in monolayer cultures and compression of chondrocytes in hydrogels or explants generally leads to anabolic signalling cascades and protective effects. For example, aggrecan and collagen type II gene expression was increased by cyclic pressure-induced strain, hydrostatic pressure or fluidinduced shear stress in chondrocyte monolayers [57-59]. In agarose, dynamic compression at low frequencies increased cell proliferation and proteoglycan synthesis following 2 or 21 days of stimulation [60-63]. In cartilage explants, cyclic compression at frequencies of 0.01 to $1 \mathrm{~Hz}$ increased proteoglycan synthesis and gene expression of extracellular matrix constituents, aggrecan, fibronectin and cartilage oligomeric matrix protein (COMP) $[20,22,64-66]$. However, results from in vitro studies are variable and appear to be dependent on the duration and type of compression regime employed and whether loading was applied during early or late cultures $[60,67-70]$. In addition, direct comparison may prove difficult between findings from 3D biomaterial constructs and explant cultures, since both systems have inherent disadvantages. For example, 3D agarose models do not replicate the physiological loading environment of cartilage and are generally cultured for relatively short time periods (hours to weeks). For explants, it is difficult to separate the contribution of the multiple mechanical and physiochemical changes which influence the intracellular pathways and regulate cell function in a spatial and temporal manner. In contrast, in vivo animal models facilitate longterm studies within a physiologically relevant environment.
However, such models are limited in terms of translating the findings to humans. Nevertheless, information regarding the importance of defining the optimal mechanical parameters required for mechanical conditioning and biosynthesis of anabolic proteins still needs to be established.

\section{Nonphysiological Mechanical Stimuli and Cartilage Destruction}

4.1. Abnormal Mechanical Loading Effects on Signal Transduction Pathways. Chondrocytes will respond to excessive mechanical signals by disrupting the composition and structure of the extracellular matrix which reduces the biomechanical integrity of cartilage. Previous in vitro studies have demonstrated that mechanical loading, representing an injurious or traumatic response, activates the integrin receptors which stimulate stress-induced intracellular pathways, leading to the production of proinflammatory cytokines such as interleukin-1 (IL-1) and tumour necrosis factor- $\alpha$ $(\mathrm{TNF} \alpha)$. These cytokines disturb the normal remodelling activities of chondrocytes by increasing production of proteolytic enzymes such as matrix metalloproteinases (MMPs) and aggrecanases (ADAMTS), a process mediated by nitric oxide $(\mathrm{NO})$, prostaglandin $\mathrm{E}_{2}\left(\mathrm{PGE}_{2}\right)$ and reactive oxygen species (ROS) [71-74]. Furthermore, the enhanced levels of proteinase enzymes cleave both collagens and proteoglycans, resulting in an increase in matrix fragments which stimulate abnormal integrin signals. The accumulation of matrix fragments enhance catabolic protease-driven pathways that override anabolic events and contribute to eventual loss of matrix components and structural damage [75-79]. Abnormal mechanical stimuli are likely to contribute to matrix damage which might shift balance of cell metabolism and lead to the onset of OA. In a recent study, surgical joint destabilisation in rodents for four weeks resulted in an increased expression of TGF $\beta 2$, insulin like growth factor-binding protein (IGFBP), MMP-2, 12, 13 and 14, ADAMTS5, Toll-like receptor 2 (TLR-2), prostaglandin E synthase (PGES), tumour necrosis factor-stimulated gene 6 (TSG-6), and Wnt-16 [80]. The animal model represents early OA tissue and is in agreement with microarray studies, which revealed changes in MMP13, COL2A1, and ADAMTS5 in OA cartilage [81, 82]. In addition, several surgical, transgenic or knockout mouse models have provided rapid insights into the mechanisms that control disease progression [83]. In mice, ADAMTS4/5 double knockout and reduced discoidin domain receptor 2 (DDR-2) activation prevents OA progression [84-86]. However, these studies did not provide any information on the mechanical load-induced effects making it difficult to correlate the findings with human disease.

Recent studies utilised a dietary model of obesity to examine the combined effect of mechanical overload and inflammatory mediators in cartilage degeneration $[87,88]$. C57BL/6J mice fed with a high-fat diet increased serum levels of leptin, adiponectin and IL- $1 \alpha$ leading to degenerative changes observed in knee OA [89]. The studies in mice correlate with clinical findings which found elevated levels of leptin, adiponectin, and resistin in osteoarthritic synovial 


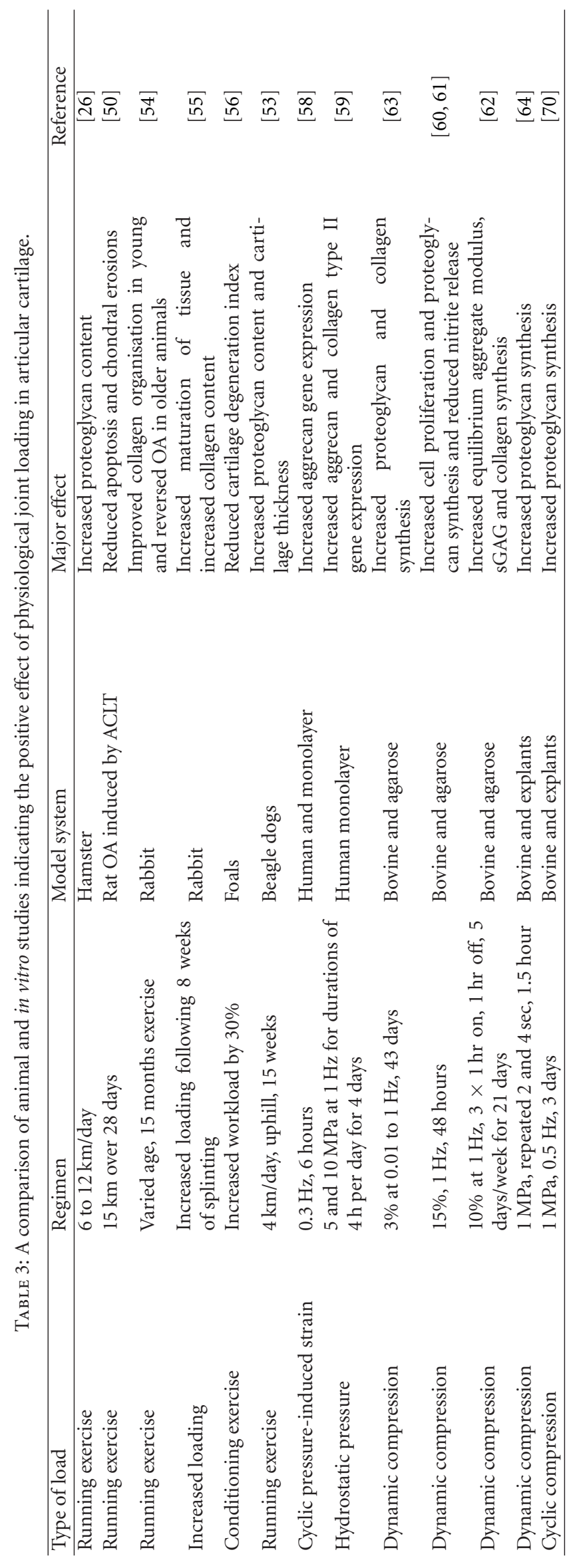


fluid $[90,91]$. The adipokine levels were found to correlate with body mass index and were greater in female subjects, indicating a high prevalence of OA in women $[91,92]$. In vitro studies demonstrate dose-dependent catabolic and anabolic effects of leptin in chondrocytes, leading to matrix remodelling and/or breakdown. Leptin synergises with IL-1 and was shown to increase NO production leading to MMP activation, apoptosis, and matrix degradation [93, 94]. Furthermore, leptin activates the RhoA/ROCK pathway leading to LIMK1 and cofilin-2 phosphorylation and cytoskeletal re-organisation in chondrocytes [95]. Taken together, these findings indicate that both obesity and mechanical overload influences normal chondrocyte function and contributes to an increase in the incidence and rate of progression of OA.

A number of in vitro models have been developed, which examine the effects of various compression regimens on signal transduction pathways. In cartilage explants, 50\% static compression for 24 hours increased expression of MMP-3, 9, and 13 and reduced aggrecan and collagen type II within 1 to 2 hours following loading [96-99]. The downregulation of matrix components by static compression was mediated by the interleukin-1 (IL-1) receptor and involves activation of members of the mitogen activation protein kinase (MAPK) family. Static compression differentially stimulates activation of extracellular signal-regulated kinase 1/2 (ERK 1/2), p38 MAPK and SAPK/ERK kinase-1 (SEK1) in a time-dependent manner [96, 100-103]. Several studies demonstrate that IL-1 will additionally stimulate the MAPK pathway and increase MMP levels which reduce proteoglycan synthesis in chondrocytes [104-106]. Both IL-1 and static compression may, therefore, share a global pathway and elicit a catabolic response mediated by members of the MAPK family. However, MAPK activation by static compression was most often transient and was reported to be dependent on the magnitude of applied stress and duration of load [100]. In contrast, cyclic compression for 30 min activates ERK 1/2 and JNK, increased AP-1 binding and expression of MMP3 and 13, leading to an increase in matrix components in chondrocytes cultured on a calcium polyphosphate substrate [107]. The sequential activation of the MAPK, AP-1, and MMP pathway occurred before matrix degradation and suggests that short-term continuous compression may induce tissue remodelling via these signalling mediators.

The pathways of interactions between non-physiological mechanical signals and inflammatory cytokines will, therefore, involve a number of signalling routes (Figure 1). The actin cytoskeleton plays an important role in mediating the effects of mechanical stimuli on nuclear deformation and cell metabolism. Remodelling of the actin cytoskeleton and disruption of the focal adhesion network leads to focal adhesion kinase (FAK) and Src activation, which stimulate the MAPK cascade. Disruption of the golgi apparatus and cytoskeletal proteins by static compression results in overall loss of mechanical properties leading to a reduction in aggrecan and collagen type II gene expression [108-114]. Tensile or compressive loading at high magnitudes (10 to $15 \%)$ for longer periods increased expression of MMP-1,
3, 9, IL-1 $\beta$, and TNF $\alpha$ and production of $\mathrm{NO}$ and $\mathrm{PGE}_{2}$ [115-117]. Upregulation of the inducible nitric oxide synthase (iNOS) and cyclo-oxygenase-2 (COX-2) enzymes will lead to several effects in chondrocytes including increased cytokine production, MMP activation, ROS production, and apoptosis [118-121]. The induction of cell death by fluidinduced shear stress involves protein kinase (PKB) activation and suppression of phosphatidylinositol 3-kinase (PI3-K), which inhibits antioxidant capacity leading to apoptosis $[122,123]$. In addition, exposure of T/C-28a 2 chondrocytes to high levels of shear stress increased $\mathrm{PGE}_{2}$ production and IL-6 expression leading to matrix degradation and chondrocyte apoptosis $[124,125]$. The induction of IL-6 was time and magnitude dependent and involved cAMP, protein kinase A (PKA), and PI3-K/Akt-dependent NF $\kappa$ B activation. Prolonged application of shear stress for up to 72 hours increased expression of IL- $1 \beta$, COX-2 and L-prostaglandin $D$ synthase (L-PGDS) leading to ROS production and matrix degradation in T/C-28a2 cells [126]. Furthermore, injurious cyclic or impact loading increased fibronectin synthesis, MMP-3 gene expression, collagen damage, and proteoglycan breakdown in cartilage explants $[127,128]$. Overall, these studies demonstrate that the expression of proteins involved in matrix remodelling and catabolism dominate over anabolic signalling events in chondrocytes subjected to abnormal mechanical stimuli.

\section{Chondroprotective Effects of Mechanical Loading}

5.1. Signalling Pathways Activated by Physiological Mechanical Stimuli. Evidence from in vitro studies demonstrate that mechanical signals within a physiological range of intensity, duration and frequency have potent anti-inflammatory effects which counteract the catabolic signals induced by IL$1 \beta$ or TNF $\alpha$ (Figure 2). For example, cyclic tensile strain of low magnitudes ( 3 to $8 \%$ ) at $0.25 \mathrm{~Hz}$ inhibits the expression of iNOS, COX-2, MMP-9 and 13 and increased TIMPII synthesis in chondrocyte monolayers cultured with IL$1 \beta$ [129]. The downregulation of the catabolic genes by cyclic tensile strain leads to the reduction of $\mathrm{NO}$ and $\mathrm{PGE}_{2}$ levels and increased synthesis of GAGs, aggrecan and collagen type II $[117,130,131]$. In chondrocytes cultured in agarose constructs, $15 \%$ dynamic compression at $1 \mathrm{~Hz}$ counteracts IL- $1 \beta$-induced iNOS and COX-2 expression and production of $\mathrm{NO}$ and $\mathrm{PGE}_{2}[132,133]$. Tensile and compressive loading inhibit the nuclear factor-kappa $\mathrm{B}$ $(\mathrm{NF} \kappa \mathrm{B})$ signal transduction pathway leading to a suppression of iNOS, COX-2, and MMP gene expression [134, 135]. Mechanical stimuli may inhibit cytoplasmic dissociation of $\mathrm{NF} \kappa \mathrm{B}$ from inhibitory $\kappa \mathrm{B}-\alpha(\mathrm{I} \kappa \mathrm{B}-\alpha)$, which prevents nuclear translocation of the p65/p50 dimers and/or proteolytic degradation of I $\kappa \mathrm{B}-\alpha$ by two I $\kappa \mathrm{B}$-specific kinases (IKK $\alpha$ and $\operatorname{IKK} \beta)$. This effect switches off transcription for the proinflammatory genes. Both IL- $1 \beta$ and mechanical stimuli interferes with the $\mathrm{NF} \kappa \mathrm{B}$ cascade and either aggravates or counteracts the induction of several catabolic genes induced by IL- $1 \beta$. However, a noticeable response in the mechanical 
Non-physiological mechanical stimuli

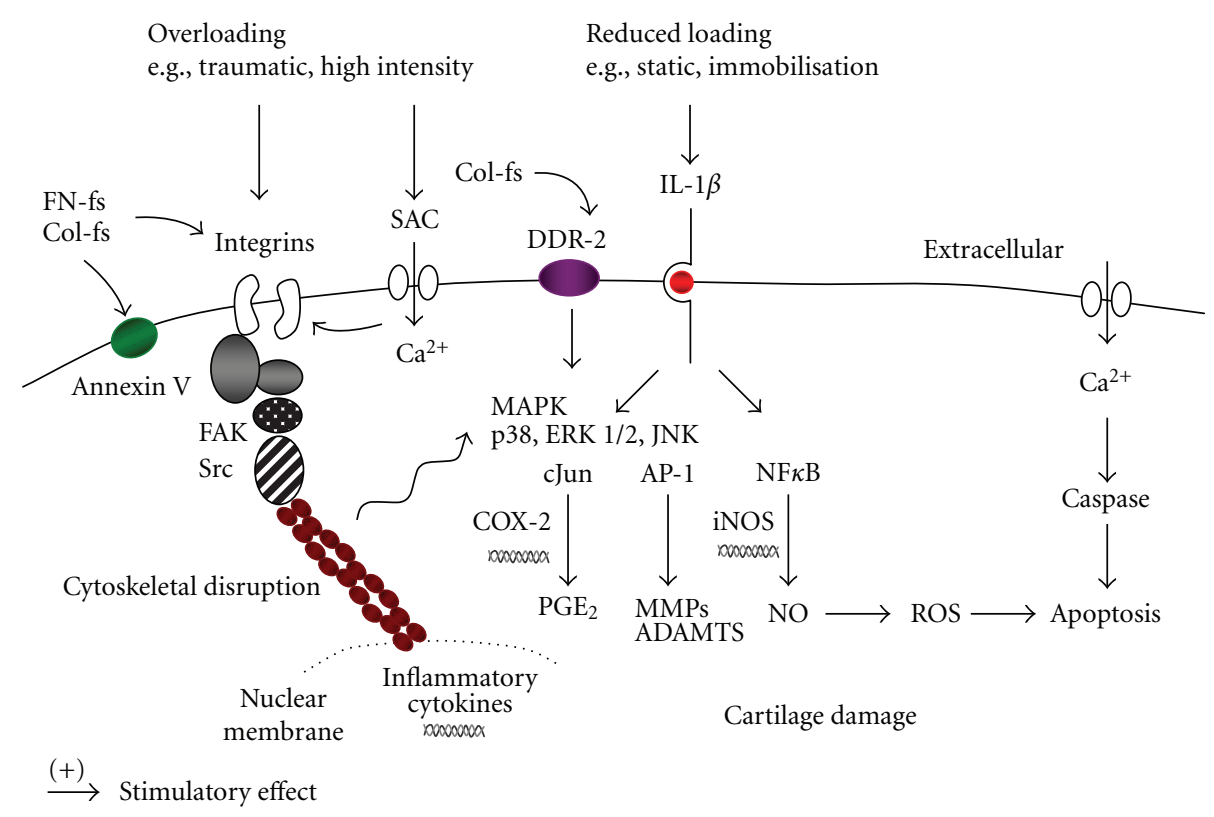

FIGURE 1: Effect of nonphysiological mechanical stimuli on signal transduction pathways in chondrocytes. Overloading activates the $\alpha 5 \beta 1$ integrin which disrupts the actin cytoskeletal network and stimulates members of the nuclear factor-kappa B (NF $\kappa$ B) and mitogen activated protein kinase (MAPK) family. These factors increase the production of nitric oxide (NO), proteolytic enzymes (MMP-1, 3, 8, and 13), ADAMTS (4 and 5), reactive oxygen species (ROS), cytokines (IL-1, TNF $\alpha$ ), and prostaglandins (PGE 2 ), which mediate cartilage damage. Mechanical signals may indirectly interact with the stretch-activated ion channels (SACs) or increase intracellular calcium levels, which stimulate caspase production ( 3 and 9 ) leading to apoptosis. The protease enzymes increase catabolic activities and accelerate tissue damage via production of fibronectin ( $\mathrm{FN}-\mathrm{fs}$ ) or collagen fragments (Col-fs), which bind to the integrins, annexin $\mathrm{V}$, discoidin domain receptor 2 (DDR-2), and induce cytokines. Reduced loading (e.g., static and immobilisation) stimulates the IL-1 receptor which activates ERK1/2, AP-1 and MMPs leading to reduced aggrecan and collagen type II synthesis.

loading studies was the partial effect of NF $\kappa \mathrm{B}$ inhibitors on downregulating the pro-inflammatory response. The gene expression data, therefore, support $\mathrm{NF} \kappa \mathrm{B}$-dependent and independent mechanisms, suggesting cross-talk with other pathways. For instance, a number of overlapping genes are regulated by the $\mathrm{NF} \kappa \mathrm{B}$ and MAPK signal transduction pathways. However, the precise sequence of events which lead to alterations in $\mathrm{NF} \kappa \mathrm{B}$ or MAPK activity by physiological mechanical signals have yet to be fully explored.

The critical mechanosensitive components include the integrins and cytoskeletal proteins (Figure 2). Previous in vitro studies have shown a role for the integrins in mediating the compression-induced synthesis of matrix components [136-140]. Perturbation of the cell membrane induces integrin conformational changes which promote binding to adaptor proteins (e.g., talin, vinculin, $\alpha$-actinin, paxillin, and zyxin) and interactions with other membrane receptors such as growth factors and stretch-activated ion channels (SACs). The adaptor proteins form the focal adhesion complex which links the integrins to the contractile microfilament bundles, thereby forming a molecular bridge between the extracellular matrix and the cytoskeleton. An intact cytoskeleton is required for normal mechanotransduction and mediates phosphorylation of FAK, paxillin, and Src leading to MAPK activation or secretion of interleukin-4 (IL-4) $[137,138,141-$ 143]. Substance $P$ is upstream of IL-4 and may act through the NK1 receptor, thereby inducing IL-4 release. It is plausible that IL-4 released through an integrin-mediated mechanotransduction pathway will accumulate and contribute to a pool of soluble anti-inflammatory mediators which block signals induced by IL- $1 \beta$. For example, compressive loading and/or stimulation with IL- 4 counteracts IL- $1 \beta$ induced NO and $\mathrm{PGE}_{2}$ production, MMP-13 expression and stimulates matrix synthesis $[144,145]$. Physiological mechanical signals may, therefore, increase the transport of soluble factors which enhance the chondroprotective effects in cartilage.

Moreover, mechanical stimuli may induce ERK due to the release of basic fibroblast growth factor (FGF-2) or cause cell membrane hyperpolarisation leading to an influx of calcium or sodium ions through putative mechanosensitive ion channels $[141,146,147]$. It is possible that membrane deformation induces colocalisation of ion channels with integrin clusters and cytoskeletal complexes resulting in activation of downstream signalling events. For example, the entry of calcium through mechanosensitive ion channels will influence the activity of the constitutive isoform of 


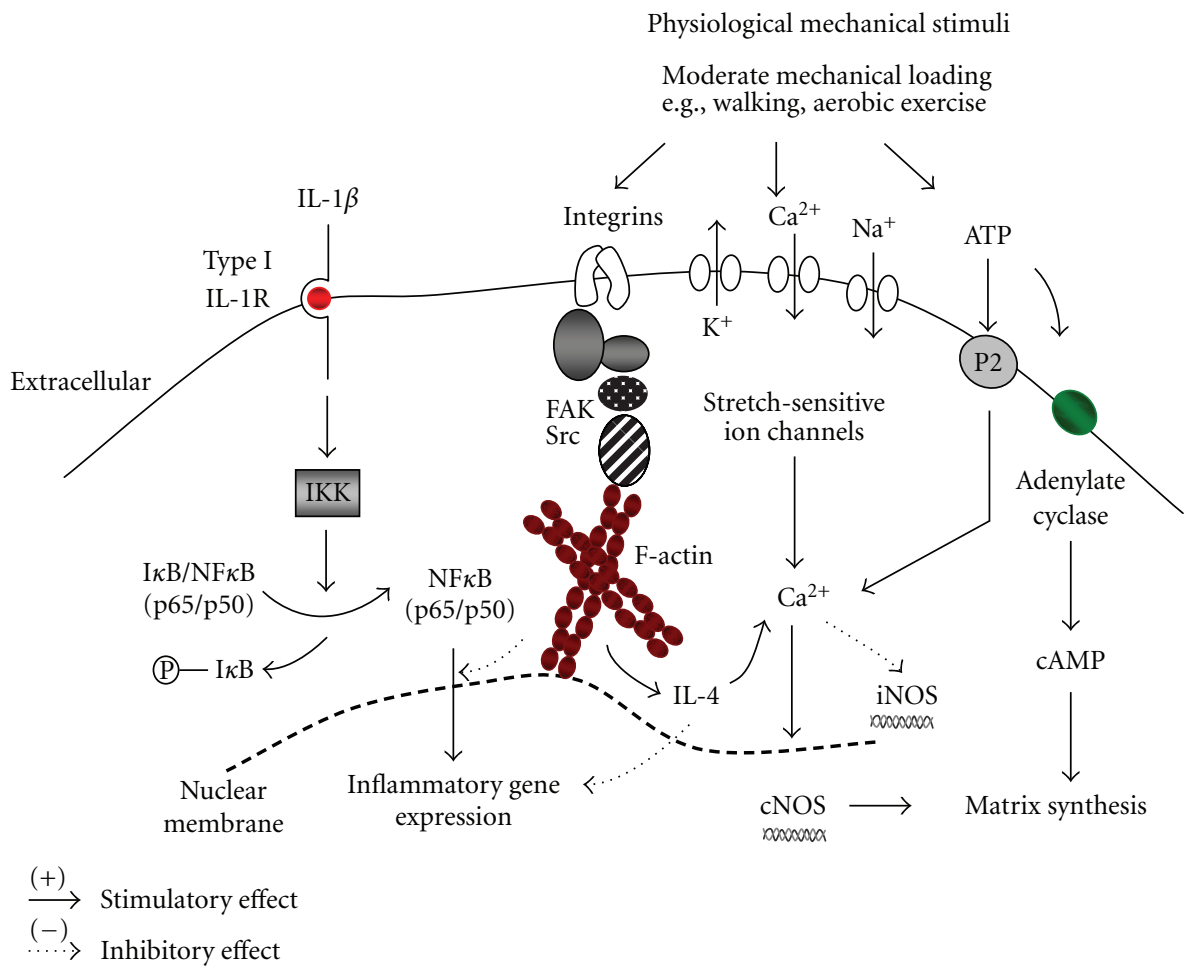

FIGURE 2: Model depicting the potential protective effects of physiological mechanical stimuli in chondrocytes stimulated with interleukin$1 \beta$ (IL-1 $\beta$ ). Moderate mechanical loading induces a number of signalling cascades which leads to the production of extracellular matrix components. Mechanical loading will stimulate integrin-mediated release of interleukin-4 (IL-4) via actin cytoskeleton, mechanical perturbation of stretch-sensitive calcium or sodium channels, or stimulation of a purinergic pathway involving ATP release and subsequent purinoreceptor (P2) or cAMP activation. The loading-induced calcium may cause instability of inducible nitric oxide synthase (iNOS) mRNA or increase transport of interleukin-4 (IL-4), which blocks catabolic effects. In the presence of IL- $1 \beta$, mechanical stimuli inhibit cytoplasmic dissociation of $\mathrm{NF} \kappa \mathrm{B}$ from inhibitory $\kappa \mathrm{B}-\alpha(\mathrm{I} \kappa \mathrm{B}-\alpha)$, which prevents nuclear translocation of the p65/p50 dimers and/or proteolytic degradation of $\mathrm{I} \kappa \mathrm{B}-\alpha$ by I $\kappa \mathrm{B}$-specific kinases (IKK) or impair I $\kappa \mathrm{B}-\alpha$ degradation, thereby switching off transcription for the pro-inflammatory genes.

NOS (cNOS) and regulate calcium/calmodulin binding, $\mathrm{PLC} / \mathrm{IP}_{3}$ activation, $\mathrm{NO}$ production, and aggrecan gene expression [141, 148, 149]. In contrast, the stability of iNOS mRNA has been reported to be reduced by increased calcium, suggesting a possible anabolic route which blocks IL- $1 \beta$-induced signals [150]. Previous studies demonstrate the involvement of a purinergic pathway in mediating mechanical load-induced ATP release and stimulation of anabolic activities [151, 152]. The enhanced ATP levels increased cyclic AMP by adenylate cyclase leading to changes in gene expression [96]. In microarray studies, the increased levels of BMP-2, inhibin $\beta \mathrm{A} /$ activin and prostaglandins suggest a possible protective mechanism [82]. Furthermore, the cAMP-responsive element-binding protein (CBP)/p300interacting transactivator with ED-rich tail 2 (CITED2) has chondroprotective effects and mediates suppression of MMPs in C28/I12 chondrocytes subjected to moderate shear stress or hydrostatic pressure by competing with the transcription factor, Ets-1 [153, 154]. In rodents, one hour of daily passive motion inhibits MMP-1 expression and upregulates CITED2 [154]. These studies clearly identify a number of routes involved in chondroprotection and are illustrated in Figure 2.

\section{Future Therapies by Combined Exercise and Chondroprotective Agents}

The need for novel pharmacological agents which provide effective long-term pain relief and have disease modifying properties for OA treatments is, as yet, unmet. Direct delivery of drugs such as glucocorticoid and hyaluronic acid formulations into the affected joint, do not retard the disease process and may provide only short-term pain relief [155]. The development of novel drugs such as lipid-based formulations and nanoparticles in combination with controlled exercise therapy may provide an alternative strategy in this challenging area of research. Such therapies may be aimed at blocking the pro-inflammatory and proteolytic pathways, thereby allowing the beneficial effects of targeted anabolic exercise regimens. Experimental studies suggest that such options may be of value. For example, intra-articular injection of the IL-1 receptor antagonist (IL-1Ra) was reported to block IL- $1 \beta$ actions and reduce OA disease progression in a canine OA model [156]. In rodents, intra-articular injection of IL-4 decreased NO production and prevents cartilage breakdown, whilst in cartilage explants and agarose, growth factors such as IGF-1 or TGF $\beta$ in combination with 
mechanical stimuli enhance matrix synthesis $[144,145,157-$ 159]. Furthermore, intra-articular injection of leptin in the rat knee joint stimulates proteoglycan synthesis via increased production of IGF- 1 and TGF $\beta 1$ [92]. The combined effect of exercise therapy in conjunction with these chondroprotective agents is not known and merits further investigation.

A further option is to develop agents which synergise with physiological mechanical loading or which block the signal transduction pathways activated by abnormal mechanical stimuli. Stimulation of mechanoreceptors releases several soluble mediators in chondrocytes including ROS, prostaglandins, cytokines, growth factors, and neuropeptides. These mediators activate downstream signalling events that regulate gene expression and cell function. For example, anti-inflammatory cytokines (IL-4 and IL-10), growth factors (TGF $\beta$, IGF-1, and FGF-2) and transcriptional regulators (CITED2) synergise with mechanical stimuli and enhance the production of matrix components $[144,145$, 154, 160]. Furthermore, physiological mechanical signals antagonise the effects of catabolic mediators involving pro-inflammatory cytokines (IL-1 $\beta$ ), transcription factors $(\mathrm{NF} \kappa \mathrm{B}), \mathrm{MAPKs}$, and enzymes (NOS, COX, and MMPs) [133-135, 161, 162]. Mechanical stimulation will increase tension at the cell surface and activate the integrins which are bound to several matrix proteins. Blocking integrin function with antibodies or small molecules has been shown to decrease oxidative damage and improve neurological function following spinal cord injury [163]. Targeting specific ion channels will allow modification of the cells response since mechanical stimuli differentially activates ion channels in normal and OA chondrocytes. Indeed, as the chondrocyte channelome becomes better defined and the roles for these molecules in regulating mechanotransduction become clearer, an increase in the range of potential therapeutic targets will emerge. In this context, N-methyl-D-aspartic acid receptor (NMDAR) may be a novel therapeutic target for OA. NMDAR appears to be necessary for mechanical signalling events in normal and OA chondrocytes [164, 165]. However, the downstream responses are different. In normal chondrocytes, NMDAR mediates mechanical loading-induced activation of small conductance calciumdependent sodium (SK) channels. In OA chondrocytes, mechanical stimuli opens tetrodotoxin sensitive sodium channels leading to inflammatory gene expression. NMDAR antagonists which block the pro-inflammatory effect are being developed for the treatment of diseases in the central nervous system and drugs such as Memantine are used clinically. Thus, agents which specifically target the functional distinct subtypes of NMDAR will have preferential effects in peripheral tissues and could block mechanical signal induced catabolic pathways.

In addition, matrix deformation will cause bending of the primary cilia which stimulates connexin 43 (Cx43) hemichannels leading to ATP release and purinergic receptor activation [166, 167]. Deficiency in either the P2X or P2Y receptors will result in reduced responsiveness to mechanical signals leading to new pathways which are catabolic and, therefore, compromise tissue structural properties [168]. Overall, these studies provide further insights on the critical mediators which could be used to promote mechanotherapy for OA. However, pharmacological intervention strategies which either antagonise or enhance the mechanotransduction process are likely to prove difficult. Normal and OA chondrocytes from diseased joints transmit mechanical signals via the $\alpha 5 \beta 1$ integrin, resulting in markedly different downstream signalling events. For example, mechanical stimulation of normal chondrocytes release the chondroprotective IL- 4 in contrast to OA cells which produce IL- $1 \beta$ [169]. It is possible that chondrocytes from OA cartilage have been reprogrammed to respond differently to their altered mechanical environment, and it may be necessary to target structural components of the cell such as the actin cytoskeleton [170]. This may allow reversal of biomechanical changes developed during OA disease progression allowing the beneficial effects of moderate exercise to be gained at the tissue level.

\section{Conclusions}

The importance of mechanical loading in maintaining healthy joints and normal tissue remodelling has long been recognised. Previous in vitro studies continue to support the hypothesis that moderate mechanical loading is necessary to maintain healthy cartilage. If joints are insufficiently loaded, chondrocyte metabolism shifts in favour of catabolism. Similarly, traumatic or excessive joint loading leads to cartilage degeneration and OA. Emerging evidence suggests that physiological joint loading could be used to counteract the inflammatory pathways and restore anabolic activities. Further investigations into the chondroprotective mechanisms are likely to be highly informative and will reveal novel therapeutic targets for OA treatments.

\section{Acknowledgments}

The authors would like to acknowledge funding from the $\mathrm{AO}$ Research Fund of the AO Foundation (S-09-83-C) and the Arthritis Research UK (19646 and 17026).

\section{References}

[1] J. A. Buckwalter and N. E. Lane, "Athletics and osteoarthritis," American Journal of Sports Medicine, vol. 25, no. 6, pp. 873-881, 1997.

[2] C. Stehling, A. Luke, R. Stahl et al., "Meniscal T1rho and T2 measured with 3.0T MRI increases directly after running a marathon," Skeletal Radiology, pp. 1-11, 2010.

[3] T. D. Spector and D. J. Hart, "Radiological evaluation of osteoarthritis," Revue du Praticien, vol. 46, no. 19, pp. S15S21, 1996.

[4] E. M. Roos and L. Dahlberg, "Positive effects of moderate exercise on glycosaminoglycan content in knee cartilage: a four-month, randomized, controlled trial in patients at risk of osteoarthritis," Arthritis and Rheumatism, vol. 52, no. 11, pp. 3507-3514, 2005.

[5] E. L. Radin, M. G. Ehrlich, R. Chernack, P. Abernethy, I. L. Paul, and R. M. Rose, "Effect of repetitive impulsive loading on the knee joints of rabbits," Clinical Orthopaedics and Related Research, vol. 131, pp. 288-293, 1978. 
[6] C. Muehleman, D. Bareither, K. Huch, A. A. Cole, and K. E. Kuettner, "Prevalence of degenerative morphological changes in the joints of the lower extremity," Osteoarthritis and Cartilage, vol. 5, no. 1, pp. 23-37, 1997.

[7] H. J. Mankin and J. A. Buckwalter, "Restoration of the osteoarthrotic joint," The Journal of Bone and Joint Surgery, vol. 78, no. 1, pp. 1-2, 1996.

[8] I. Kiviranta, M. Tammi, J. Jurvelin, J. Arokoski, A. M. Saamanen, and H. J. Helminen, "Articular cartilage thickness and glycosaminoglycan distribution in the canine knee joint after strenuous running exercise," Clinical Orthopaedics and Related Research, no. 283, pp. 302-308, 1992.

[9] J. Arokoski, I. Kiviranta, J. Jurvelin, M. Tammi, and H. J. Helminen, "Long-distance running causes site-dependent decrease of cartilage glycosaminoglycan content in the knee joints of beagle dogs," Arthritis and Rheumatism, vol. 36, no. 10, pp. 1451-1459, 1993.

[10] T. Lapvetelainen, T. Nevalainen, J. J. Parkkinen et al., "Lifelong moderate running training increases the incidence and severity of osteoarthritis in the knee joint of C57BL mice," Anatomical Record, vol. 242, no. 2, pp. 159-165, 1995.

[11] J. P. A. Arokoski, J. S. Jurvelin, U. Väätäinen, and H. J. Helminen, "Normal and pathological adaptations of articular cartilage to joint loading," Scandinavian Journal of Medicine and Science in Sports, vol. 10, no. 4, pp. 186-198, 2000.

[12] P. A. Torzilli, R. Grigiene, J. Borrelli Jr., and D. L. Helfet, "Effect of impact load on articular cartilage: cell metabolism and viability, and matrix water content," Journal of Biomechanical Engineering, vol. 121, no. 5, pp. 433-441, 1999.

[13] J. E. Jeffrey, D. W. Gregory, and R. M. Aspden, "Matrix damage and chondrocyte viability following a single impact load on articular cartilage," Archives of Biochemistry and Biophysics, vol. 322, no. 1, pp. 87-96, 1995.

[14] A. M. Loening, I. E. James, M. E. Levenston et al., "Injurious mechanical compression of bovine articular cartilage induces chondrocyte apoptosis," Archives of Biochemistry and Biophysics, vol. 381, no. 2, pp. 205-212, 2000.

[15] R. M. Aspden, J. E. Jeffrey, and L. V. Burgin, "Impact loading of articular cartilage," Osteoarthritis and Cartilage, vol. 10, no. 7, pp. 588-590, 2002.

[16] J. E. Jeffrey and R. M. Aspden, "The biophysical effects of a single impact load on human and bovine articular cartilage," Proceedings of the Institution of Mechanical Engineers $H$, vol. 220, no. 6, pp. 677-686, 2006.

[17] B. Kurz, M. Jin, P. Patwari, D. M. Cheng, M. W. Lark, and A. J. Grodzinsky, "Biosynthetic response and mechanical properties of articular cartilage after injurious compression," Journal of Orthopaedic Research, vol. 19, no. 6, pp. 1140-1146, 2001.

[18] C. T. Chen, N. Burton-Wurster, G. Lust, R. A. Bank, and J. M. Tekoppele, "Compositional and metabolic changes in damaged cartilage are peak- stress, stress-rate, and loadingduration dependent," Journal of Orthopaedic Research, vol. 17, no. 6, pp. 870-879, 1999.

[19] C. T. Chen, N. Burton-Wurster, C. Borden, K. Hueffer, S. E. Bloom, and G. Lust, "Chondrocyte necrosis and apoptosis in impact damaged articular cartilage," Journal of Orthopaedic Research, vol. 19, no. 4, pp. 703-711, 2001.

[20] F. Guilak, B. C. Meyer, A. Ratcliffe, and V. C. Mow, "The effects of matrix compression on proteoglycan metabolism in articular cartilage explants," Osteoarthritis and Cartilage, vol. 2, no. 2, pp. 91-101, 1994.
[21] R. L. Y. Sah, Y. J. Kim, J. Y. H. Doong, A. J. Grodzinsky, A. H. K. Plaas, and J. D. Sandy, "Biosynthetic response of cartilage explants to dynamic compression," Journal of Orthopaedic Research, vol. 7, no. 5, pp. 619-636, 1989.

[22] Y. J. Kim, A. J. Grodzinsky, and A. H. K. Plaas, "Compression of cartilage results in differential effects on biosynthetic pathways for aggrecan, link protein, and hyaluronan," Archives of Biochemistry and Biophysics, vol. 328, no. 2, pp. 331-340, 1996.

[23] M. Palmoski, E. Perricone, and K. D. Brandt, "Development and reversal of a proteoglycan aggregation defect in normal canine knee cartilage after immobilization," Arthritis and Rheumatism, vol. 22, no. 5, pp. 508-517, 1979.

[24] J. Jurvelin, I. Kiviranta, M. Tammi, and J. H. Helminen, "Softening of canine articular cartilage after immobilization of the knee joint," Clinical Orthopaedics and Related Research, no. 207, pp. 246-252, 1986.

[25] J. C. Copray, H. W. B. Jansen, and H. S. Duterloo, "Effects of compressive forces on proliferation and matrix synthesis in mandibular condylar cartilage of the rat in vitro," Archives of Oral Biology, vol. 30, no. 4, pp. 299-304, 1985.

[26] I. G. Otterness, J. D. Eskra, M. L. Bliven, A. K. Shay, J. P. Pelletier, and A. J. Milici, "Exercise protects against articular cartilage degeneration in the hamster," Arthritis and Rheumatism, vol. 41, no. 11, pp. 2068-2076, 1998.

[27] S. Hinterwimmer, M. Krammer, M. Krötz et al., "Cartilage atrophy in the knees of patients after seven weeks of partial load bearing," Arthritis and Rheumatism, vol. 50, no. 8, pp. 2516-2520, 2004.

[28] Vanwanseele, F. Eckstein, H. Knecht, E. Stüssi, and A. Spaepen, "Knee cartilage of spinal cord-injured patients displays progressive thinning in the absence of normal joint loading and movement," Arthritis and Rheumatism, vol. 46, no. 8, pp. 2073-2078, 2002.

[29] B. Vanwanseele, F. Eckstein, H. Knecht, A. Spaepen, and E. Stüssis, "Longitudinal analysis of cartilage atrophy in the knees of patients with spinal cord injury," Arthritis and Rheumatism, vol. 48, no. 12, pp. 3377-3381, 2003.

[30] J. Haapala, J. P. A. Arokoski, M. M. Hyttinen et al., "Remobilization does not fully restore immobilization induced articular cartilage atrophy," Clinical Orthopaedics and Related Research, no. 362, pp. 218-229, 1999.

[31] A. M. Saamanen, M. Tammi, J. Jurvelin, I. Kiviranta, and H. J. Helminen, "Proteoglycan alterations following immobilization and remobilization in the articular cartilage of young canine knee (stifle) joint," Journal of Orthopaedic Research, vol. 8, no. 6, pp. 863-873, 1990.

[32] J. Jurvelin, I. Kiviranta, A. M. Saamanen, M. Tammi, and H. J. Helminen, "Partial restoration of immobilization-inducing softening of canine articular cartilage after remobilization of the knee (stifle) joint," Journal of Orthopaedic Research, vol. 7, no. 3, pp. 352-358, 1989.

[33] M. J. Palmoski and K. D. Brandt, "Running inhibits the reversal of atrophic changes in canine knee cartilage after removal of a leg cast," Arthritis and Rheumatism, vol. 24, no. 11, pp. 1329-1337, 1981.

[34] J. Haapala, J. Arokoski, J. Pirttimäki et al., "Incomplete restoration of immobilization induced softening of young beagle knee articular cartilage after 50-week remobilization," International Journal of Sports Medicine, vol. 21, no. 1, pp. 76$81,2000$.

[35] J. A. Buckwalter, "Articular cartilage: injuries and potential for healing," Journal of Orthopaedic and Sports Physical Therapy, vol. 28, no. 4, pp. 192-202, 1998. 
[36] K. M. Jordan, N. K. Arden, M. Doherty et al., "EULAR recommendations 2003: $\mathrm{rn}$ evidence based approach to the management of knee osteoarthritis: report of a task force of the Standing Committee for International Clinical Studies including therapeutic trials (ESCISIT)," Annals of the Rheumatic Diseases, vol. 62, no. 12, pp. 1145-1155, 2003.

[37] M. Fransen, S. McConnell, and M. Bell, “Therapeutic exercise for people with osteoarthritis of the hip or knee. A systematic review," Journal of Rheumatology, vol. 29, no. 8, pp. 17371745, 2002.

[38] E. Roddy, W. Zhang, and M. Doherty, "Aerobic walking or strengthening exercise for osteoarthritis of the knee? A systematic review," Annals of the Rheumatic Diseases, vol. 64, no. 4, pp. 544-548, 2005.

[39] M. J. Jansen, W. Viechtbauer, A. F. Lenssen, E. J. Hendriks, and R. A. de Bie, "Strength training alone, exercise therapy alone, and exercise therapy with passive manual mobilisation each reduce pain and disability in people with knee osteoarthritis: a systematic review," Journal of Physiotherapy, vol. 57, no. 1, pp. 11-20, 2011.

[40] M. J. Jansen, E. J. Hendriks, R. A.B. Oostendorp, J. Dekker, and R. A. De Bie, "Quality indicators indicate good adherence to the clinical practice guideline on "Osteoarthritis of the hip and knee" and few prognostic factors influence outcome indicators: a prospective cohort study," European Journal of Physical and Rehabilitation Medicine, vol. 46, no. 3, pp. 337$345,2010$.

[41] P. Manninen, H. Riihimaki, M. Heliovaara, and O. Suomalainen, "Physical exercise and risk of severe knee OA requiring arthriplasty," Rheumatology, vol. 40, no. 4, pp. 432437, 2001.

[42] D. T. Felson, J. Niu, C. McClennan et al., "Knee buckling: prevalence, risk factors, and associated limitations in function," Annals of Internal Medicine, vol. 147, no. 8, pp. 534540, 2007.

[43] S. P. Messier, "Diet and exercise for obese adults with knee osteoarthritis," Clinics in Geriatric Medicine, vol. 26, no. 3, pp. 461-477, 2010.

[44] S. Perrot, S. Poiraudeau, M. Kabir-Ahmadi, and F. Rannou, "Correlates of pain intensity in Men and Women with hip and knee osteoarthritis. Results of a national survey: the French ARTHRIX study," Clinical Journal of Pain, vol. 25, no. 9, pp. 767-772, 2009.

[45] E. Vignon, J. P. Valat, M. Rossignol et al., "Osteoarthritis of the knee and hip and activity: a systematic international review and synthesis (OASIS)," Joint Bone Spine, vol. 73, no. 4, pp. 442-455, 2006.

[46] K. L. Bennell and R. S. Hinman, "A review of the clinical evidence for exercise in osteoarthritis of the hip and knee," Journal of Science and Medicine in Sport, vol. 14, no. 1, pp. 4-9, 2011.

[47] M. E. van Baar, W. J. J. Assendelft, J. Dekker, R. A. B. Oostendorp, and J. W. J. Bijlsma, "Effectiveness of exercise therapy in patients with osteoarthritis of the hip or knee: a systematic review of randomized clinical trials," Arthritis and Rheumatism, vol. 42, no. 7, pp. 1361-1369, 1999.

[48] W. H. Ettinger Jr., R. Burns, S. P. Messier et al., "A randomized trial comparing aerobic exercise and resistance exercise with a health education program in older adults with knee osteoarthritis: the Fitness Arthritis and Seniors Trial (FAST)," Journal of the American Medical Association, vol. 277, no. 1, pp. 25-31, 1997.

[49] M. W. Creaby, Y. Wang, K. L. Bennell et al., "Dynamic knee loading is related to cartilage defects and tibial plateau bone area in medial knee osteoarthritis," Osteoarthritis and Cartilage, vol. 18, no. 11, pp. 1380-1385, 2010.

[50] L. Galois, S. Etienne, L. Grossin et al., "Moderate-impact exercise is associated with decreased severity of experimental osteoarthritis in rats (multiple letters)," Rheumatology, vol. 42, no. 5, pp. 692-694, 2003.

[51] J. A. Buckwalter, "Osteoarthritis and articular cartilage use, disuse, and abuse: experimental studies," Journal of Rheumatology, vol. 43, pp. 13-15, 1995.

[52] I. Kiviranta, M. Tammi, J. Jurvelin, A. M. Saamanen, and H. J. Helminen, "Moderate running exercise augments glycosaminoglycans and thickness of articular cartilage in the knee joint of young Beagle dogs," Journal of Orthopaedic Research, vol. 6, no. 2, pp. 188-195, 1988.

[53] H. J. Helminen, M. M. Hyttinen, M. J. Lammi et al., "Regular joint loading in youth assists in the establishment and strengthening of the collagen network of articular cartilage and contributes to the prevention of osteoarthrosis later in life: a hypothesis," Journal of Bone and Mineral Metabolism, vol. 18, no. 5, pp. 245-257, 2000.

[54] P. Julkunen, J. Iivarinen, P. A. Brama, J. Arokoski, J. S. Jurvelin, and H. J. Helminen, "Maturation of collagen fibril network structure in tibial and femoral cartilage of rabbits," Osteoarthritis and Cartilage, vol. 18, no. 3, pp. 406-415, 2010.

[55] A. M. Säämänen, M. Tammi, I. Kiviranta, J. Jurvelin, and H. J. Helminen, "Maturation of proteoglycan matrix in articular cartilage under increased and decreased joint loading. A study in young rabbits," Connective Tissue Research, vol. 16, no. 2, pp. 163-175, 1987.

[56] P. R. van Weeren, E. C. Firth, H. Brommer et al., "Early exercise advances the maturation of glycosaminoglycans and collagen in the extracellular matrix of articular cartilage in the horse," Equine Veterinary Journal, vol. 40, no. 2, pp. 128 $135,2008$.

[57] P. Das, D. J. Schurman, and R. L. Smith, "Nitric oxide and $G$ proteins mediate the response of bovine articular chondrocytes to fluid-induced shear," Journal of Orthopaedic Research, vol. 15, no. 1, pp. 87-93, 1997.

[58] S. J. Millward-Sadler, M. O. Wright, L. W. Davies, G. Nuki, and D. M. Salter, "Mechanotransduction via integrins and interleukin- 4 results in altered aggrecan and matrix metalloproteinase 3 gene expression in normal, but not osteoarthritic, human articular chondrocytes," Arthritis and Rheumatism, vol. 43, no. 9, pp. 2091-2099, 2000.

[59] T. Ikenoue, M. C. D. Trindade, M. S. Lee et al., "Mechanoregulation of human articular chondrocyte aggrecan and type II collagen expression by intermittent hydrostatic pressure in vitro," Journal of Orthopaedic Research, vol. 21, no. 1, pp. 110 116, 2003.

[60] D. A. Lee and D. L. Bader, "Compressive strains at physiological frequencies influence the metabolism of chondrocytes seeded in agarose," Journal of Orthopaedic Research, vol. 15, no. 2, pp. 181-188, 1997.

[61] D. A. Lee, S. P. Frean, P. Lees, and D. L. Bader, "Dynamic mechanical compression influences nitric oxide production by articular chondrocytes seeded in agarose," Biochemical and Biophysical Research Communications, vol. 251, no. 2, pp. 580-585, 1998.

[62] R. L. Mauck, M. A. Soltz, C. C. B. Wang et al., "Functional tissue engineering of articular cartilage through dynamic loading of chondrocyte-seeded agarose gels," Journal of Biomechanical Engineering, vol. 122, no. 3, pp. 252-260, 2000.

[63] M. D. Buschmann, Y. A. Gluzband, A. J. Grodzinsky, and E. B. Hunziker, "Mechanical compression modulates matrix 
biosynthesis in chondrocyte/agarose culture," Journal of Cell Science, vol. 108, no. 4, pp. 1497-1508, 1995.

[64] J. J. Parkkinen, M. J. Lammi, H. J. Helminen, and M. Tammi, "Local stimulation of proteoglycan synthesis in articular cartilage explants by dynamic compression in vitro," Journal of Orthopaedic Research, vol. 10, no. 5, pp. 610-620, 1992.

[65] W. B. Valhmu, E. J. Stazzone, N. M. Bachrach et al., "Load-controlled compression of articular cartilage induces a transient stimulation of aggrecan gene expression," Archives of Biochemistry and Biophysics, vol. 353, no. 1, pp. 29-36, 1998.

[66] M. Wong, M. Siegrist, and X. Cao, "Cyclic compression of articular cartilage explants is associated with progressive consolidation and altered expression pattern of extracellular matrix proteins," Matrix Biology, vol. 18, no. 4, pp. 391-399, 1999.

[67] K. Sauerland, R. X. Raiss, and J. Steinmeyer, "Proteoglycan metabolism and viability of articular cartilage explants as modulated by the frequency of intermittent loading," Osteoarthritis and Cartilage, vol. 11, no. 5, pp. 343-350, 2003.

[68] T. T. Chowdhury, D. L. Bader, J. C. Shelton, and D. A. Lee, "Temporal regulation of chondrocyte metabolism in agarose constructs subjected to dynamic compression," Archives of Biochemistry and Biophysics, vol. 417, no. 1, pp. 105-111, 2003.

[69] B. Ackermann and J. Steinmeyer, "Collagen biosynthesis of mechanically loaded articular cartilage explants," Osteoarthritis and Cartilage, vol. 13, no. 10, pp. 906-914, 2005.

[70] J. Steinmeyer, S. Knue, R. X. Raiss, and I. Pelzer, "Effects of intermittently applied cyclic loading on proteoglycan metabolism and swelling behaviour of articular cartilage explants," Osteoarthritis and Cartilage, vol. 7, no. 2, pp. 155164, 1999.

[71] J. C. Fernandes, J. Martel-Pelletier, and J. P. Pelletier, "The role of cytokines in osteoarthritis pathophysiology," Biorheology, vol. 39, no. 1-2, pp. 237-246, 2002.

[72] Y. E. Henrotin, P. Bruckner, and J. P. L. Pujol, "The role of reactive oxygen species in homeostasis and degradation of cartilage," Osteoarthritis and Cartilage, vol. 11, no. 10, pp. 747-755, 2003.

[73] H. A. Kim and F. J. Blanco, "Cell death and apoptosis in ostearthritic cartilage," Current Drug Targets, vol. 8, no. 2, pp. 333-345, 2007.

[74] J. Martel-Pelletier, C. Boileau, J. P. Pelletier, and P. J. Roughley, "Cartilage in normal and osteoarthritis conditions," Best Practice and Research: Clinical Rheumatology, vol. 22, no. 2, pp. 351-384, 2008.

[75] G. A. Homandberg, "Potential regulation of cartilage metabolism in osteoarthritis by fibronectin fragments. In Fundamental pathways in osteoarthritis. Edited by Malemud CJ," Frontiers in Bioscience, pp. 713-730, 1997.

[76] D. L. Xie, F. Hui, and G. A. Homandberg, "Cartilage chondrolysis by fibronectin fragments is associated with release of several proteinases: Stromelysin plays a major role in chondrolysis," Archives of Biochemistry and Biophysics, vol. 307, no. 1, pp. 110-118, 1994.

[77] M. Del Carlo, D. Schwartz, E. A. Erickson, and R. F. Loeser, "Endogenous production of reactive oxygen species is required for stimulation of human articular chondrocyte matrix metalloproteinase production by fibronectin fragments," Free Radical Biology and Medicine, vol. 42, no. 9, pp. 1350-1358, 2007.
[78] H. Stanton, L. Ung, and A. J. Fosang, "The $45 \mathrm{kDa}$ collagen-binding fragment of fibronectin induces matrix metalloproteinase- 13 synthesis by chondrocytes and aggrecan degradation by aggrecanases," Biochemical Journal, vol. 364, part 1, pp. 181-190, 2002.

[79] D. Guo, L. Ding, and G. A. Homandberg, "Telopeptides of type II collagen upregulate proteinases and damage cartilage but are less effective than highly active fibronectin fragments," Inflammation Research, vol. 58, no. 3, pp. 161$169,2009$.

[80] C. T. G. Appleton, V. Pitelka, J. Henry, and F. Beier, "Global analyses of gene expression in early experimental osteoarthritis," Arthritis and Rheumatism, vol. 56, no. 6, pp. 1854-1868, 2007.

[81] F. Dell'Accio, C. De Bari, N. M. Eltawil, P. Vanhummelen, and C. Pitzalis, "Identification of the molecular response of articular cartilage to injury, by microarray screening: Wnt-16 expression and signaling after injury and in osteoarthritis," Arthritis and Rheumatism, vol. 58, no. 5, pp. 1410-1421, 2008.

[82] T. Aigner, K. Fundel, J. Saas et al., "Large-scale gene expression profiling reveals major pathogenetic pathways of cartilage degeneration in osteoarthritis," Arthritis and Rheumatism, vol. 54, no. 11, pp. 3533-3544, 2006.

[83] H. J. Helminen, A. M. Säämänen, H. Salminen, and M. M. Hyttinen, "Transgenic mouse models for studying the role of cartilage macromolecules in osteoarthritis," Rheumatology, vol. 41, no. 8, pp. 848-856, 2002.

[84] L. Xu, H. Peng, S. Glasson et al., "Increased expression of the collagen receptor discoidin domain receptor 2 in articular cartilage as a key event in the pathogenesis of osteoarthritis," Arthritis and Rheumatism, vol. 56, no. 8, pp. 2663-2673, 2007.

[85] M. K. Majumdar, R. Askew, S. Schelling et al., "Doubleknockout of ADAMTS-4 and ADAMTS-5 in mice results in physiologically normal animals and prevents the progression of osteoarthritis," Arthritis and Rheumatism, vol. 56, no. 11, pp. 3670-3674, 2007.

[86] S. S. Glasson, "In vivo osteoarthritis target validation utilizing genetically-modified mice," Current Drug Targets, vol. 8, no. 2, pp. 367-376, 2007.

[87] T. M. Griffin and F. Guilak, "Why is obesity associated with osteoarthritis? Insights from mouse models of obesity," Biorheology, vol. 45, no. 3-4, pp. 387-398, 2008.

[88] P. Pottie, N. Presle, B. Terlain, P. Netter, D. Mainard, and F. Berenbaum, "Obesity and osteoarthritis: more complex than predicted!," Annals of the Rheumatic Diseases, vol. 65, no. 11, pp. 1403-1405, 2006.

[89] T. M. Griffin, B. Fermor, J. L. Huebner et al., "Diet-induced obesity differentially regulates behavioral, biomechanical, and molecular risk factors for osteoarthritis in mice," Arthritis Research and Therapy, vol. 12, no. 4, p. R130, 2010.

[90] A. Schäffler, A. Ehling, E. Neumann et al., "Adipocytokines in synovial fluid," Journal of the American Medical Association, vol. 290, no. 13, pp. 1709-1710, 2003.

[91] N. Presle, P. Pottie, H. Dumond et al., "Differential distribution of adipokines between serum and synovial fluid in patients with osteoarthritis. Contribution of joint tissues to their articular production," Osteoarthritis and Cartilage, vol. 14, no. 7, pp. 690-695, 2006.

[92] H. Dumond, N. Presle, B. Terlain et al., "Evidence for a key role of leptin in osteoarthritis," Arthritis and Rheumatism, vol. 48, no. 11, pp. 3118-3129, 2003. 
[93] M. Otero, R. Lago, F. Lago, J. J. Reino, and O. Gualillo, "Signalling pathway involved in nitric oxide synthase type II activation in chondrocytes: synergistic effect of leptin with interleukin-1," Arthritis Research and Therapy, vol. 7, no. 3, pp. R581-R591, 2005.

[94] A. Koskinen, K. Vuolteenaho, R. Nieminen, T. Moilanen, and E. Moilanen, "Leptin enhances MMP-1, MMP-3 and MMP-13 production in human osteoarthritic cartilage and correlates with MMP-1 and MMP-3 in synovial fluid from OA patients," Clinical and Experimental Rheumatology, vol. 29, no. 1, pp. 57-64, 2011.

[95] J. Liang, J. Feng, W. K. Wu et al., "Leptin-mediated cytoskeletal remodeling in chondrocytes occurs via the RhoA/ROCK pathway," Journal of Orthopaedic Research, vol. 29, no. 3, pp. 369-374, 2011.

[96] J. B. Fitzgerald, M. Jin, D. Dean, D. J. Wood, M. H. Zheng, and A. J. Grodzinsky, "Mechanical compression of cartilage explants induces multiple time-dependent gene expression patterns and involves intracellular calcium and cyclic AMP," Journal of Biological Chemistry, vol. 279, no. 19, pp. 1950219511, 2004.

[97] M. Murata, L. J. Bonassar, M. Wright, H. J. Mankin, and C. A. Towle, "A role for the interleukin-1 receptor in the pathway linking static mechanical compression to decreased proteoglycan synthesis in surface articular cartilage," Archives of Biochemistry and Biophysics, vol. 413, no. 2, pp. 229-235, 2003.

[98] A. Fehrenbacher, E. Steck, M. Rickert, W. Roth, and W. Richter, "Rapid regulation of collagen but not metalloproteinase 1, 3, 13, 14 and tissue inhibitor of metalloproteinase 1, 2, 3 expression in response to mechanical loading of cartilage explants in vitro," Archives of Biochemistry and Biophysics, vol. 410, no. 1, pp. 39-47, 2003.

[99] P. M. Ragan, A. M. Badger, M. Cook et al., "Downregulation of chondrocyte aggrecan and type-II collagen gene expression correlates with increases in static compression magnitude and duration," Journal of Orthopaedic Research, vol. 17, no. 6, pp. 836-842, 1999.

[100] P. J. Fanning, G. Emkey, R. J. Smith, A. J. Grodzinsky, N. Szasz, and S. B. Trippel, "Mechanical regulation of mitogenactivated protein kinase signaling in articular cartilage," Journal of Biological Chemistry, vol. 278, no. 51, pp. 5094050948, 2003.

[101] K. W. Li, A. S. Wang, and R. L. Sah, "Microenvironment regulation of extracellular signal-regulated kinase activity in chondrocytes: effects of culture configuration, interleukin-1, and compressive stress," Arthritis and Rheumatism, vol. 48, no. 3, pp. 689-699, 2003.

[102] C. Bougault, A. Paumier, E. Aubert-Foucher, and F. MalleinGerin, "Molecular analysis of chondrocytes cultured in agarose in response to dynamic compression," BMC Biotechnology, vol. 8, article 71, 2008.

[103] L. Ding, E. Heying, N. Nicholson et al., "Mechanical impact induces cartilage degradation via mitogen activated protein kinases," Osteoarthritis and Cartilage, vol. 18, no. 11, pp. 1509-1517, 2010.

[104] J. A. Mengshol, M. P. Vincenti, C. I. Coon, A. Barchowsky, and C. E. Brinckerhoff, "Interleukin-1 induction of collagenase 3 (matrix metalloproteinase 13) gene expression in chondrocytes requires $\mathrm{p} 38$, c-Jun N-terminal kinase, and nuclear factor kappaB: differential regulation of collagenase 1 and collagenase 3," Arthritis and Rheumatism, vol. 43, no. 4, pp. 801-811, 2000.
[105] A. Liacini, J. Sylvester, W. Q. Li et al., "Induction of matrix metalloproteinase- 13 gene expression by TNF- $\alpha$ is mediated by MAP kinases, AP-1, and NF- $\kappa$ B transcription factors in articular chondrocytes," Experimental Cell Research, vol. 288, no. 1, pp. 208-217, 2003.

[106] M. B. Goldring and S. M. Krane, "Modulation by recombinant interleukin 1 of synthesis of types I and III collagens and associated procollagen mRNA levels in cultured human cells," Journal of Biological Chemistry, vol. 262, no. 34, pp. 16724-16729, 1987.

[107] J. N. A. De Croos, S. S. Dhaliwal, M. D. Grynpas, R. M. Pilliar, and R. A. Kandel, "Cyclic compressive mechanical stimulation induces sequential catabolic and anabolic gene changes in chondrocytes resulting in increased extracellular matrix accumulation," Matrix Biology, vol. 25, no. 6, pp. 323331, 2006.

[108] M. O. Jortikka, J. J. Parkkinen, R. I. Inkinen et al., “The role of microtubules in the regulation of proteoglycan synthesis in chondrocytes under hydrostatic pressure," Archives of Biochemistry and Biophysics, vol. 374, no. 2, pp. 172-180, 2000.

[109] J. J. Parkkinen, M. J. Lammi, A. Pelttari, H. J. Helminen, M. Tammi, and I. Virtanen, "Altered Golgi apparatus in hydrostatically loaded articular cartilage chondrocytes," Annals of the Rheumatic Diseases, vol. 52, no. 3, pp. 192-198, 1993.

[110] E. J. Blain, S. J. Gilbert, A. J. Hayes, and V. C. Duance, "Disassembly of the vimentin cytoskeleton disrupts articular cartilage chondrocyte homeostasis," Matrix Biology, vol. 25, no. 7, pp. 398-408, 2006.

[111] B. D. Idowu, M. M. Knight, D. L. Bader, and D. A. Lee, "Confocal analysis of cytoskeletal organisation within isolated chondrocyte sub-populations cultured in agarose," Histochemical Journal, vol. 32, no. 3, pp. 165-174, 2000.

[112] D. A. Lee, M. M. Knight, J. F. Bolton, B. D. Idowu, M. V. Kayser, and D. L. Bader, "Chondrocyte deformation within compressed agarose constructs at the cellular and subcellular levels," Journal of Biomechanics, vol. 33, no. 1, pp. 8195, 2000.

[113] D. R. Haudenschild, J. Chen, N. Pang et al., "Vimentin contributes to changes in chondrocyte stiffness in osteoarthritis," Journal of Orthopaedic Research, vol. 29, no. 1, pp. 20-25, 2011.

[114] W. R. Trickey, T. P. Vail, and F. Guilak, "The role of the cytoskeleton in the viscoelastic properties of human articular chondrocytes," Journal of Orthopaedic Research, vol. 22, no. 1, pp. 131-139, 2004.

[115] K. Honda, S. Ohno, K. Tanimoto et al., "The effects of high magnitude cyclic tensile load on cartilage matrix metabolism in cultured chondrocytes," European Journal of Cell Biology, vol. 79, no. 9, pp. 601-609, 2000.

[116] B. Fermor, J. Brice Weinberg, D. S. Pisetsky, M. A. Misukonis, A. J. Banes, and F. Guilak, "The effects of static and intermittent compression on nitric oxide production in articular cartilage explants," Journal of Orthopaedic Research, vol. 19, no. 4, pp. 729-737, 2001.

[117] P. Long, R. Gassner, and S. Agarwal, "Tumor necrosis factor alpha-dependent proinflammatory gene induction is inhibited by cyclic tensile strain in articular chondrocytes in vitro," Arthritis and Rheumatism, vol. 44, no. 10, pp. 23112319, 2001.

[118] M. Lotz, S. Hashimoto, and K. Kühn, "Mechanisms of chondrocyte apoptosis," Osteoarthritis and Cartilage, vol. 7, no. 4, pp. 389-391, 1999. 
[119] R. Studer, D. Jaffurs, M. Stefanovic-Racic, P. D. Robbins, and C. H. Evans, "Nitric oxide in osteoarthritis," Osteoarthritis and Cartilage, vol. 7, no. 4, pp. 377-379, 1999.

[120] J. Martel-Pelletier, N. Alaaeddine, and J. P. Pelletier, "Cytokines and their role in the pathophysiology of osteoarthritis," Frontiers in Bioscience, vol. 4, pp. D694-D703, 1999.

[121] Y. Henrotin, B. Kurz, and T. Aigner, "Oxygen and reactive oxygen species in cartilage degradation: friends or foes?" Osteoarthritis and Cartilage, vol. 13, no. 8, pp. 643-654, 2005.

[122] Z. R. Healy, N. H. Lee, X. Gao et al., "Divergent responses of chondrocytes and endothelial cells to shear stress: crosstalk among COX-2, the phase 2 response, and apoptosis," Proceedings of the National Academy of Sciences of the United States of America, vol. 102, no. 39, pp. 14010-14015, 2005.

[123] J. Borrelli Jr., K. Tinsley, W. M. Ricci, M. Burns, I. E. Karl, and R. Hotchkiss, "Induction of chondrocyte apoptosis following impact load," Journal of Orthopaedic Trauma, vol. 17, no. 9, pp. 635-641, 2003.

[124] P. Wang, F. Zhu, N. H. Lee, and K. Konstantopoulos, "Shearinduced interleukin- 6 synthesis in chondrocytes: roles of $\mathrm{E}$ prostanoid (EP) 2 and $\mathrm{EP} 3$ in $\mathrm{cAMP} /$ protein kinase A- and PI3-K/Akt-dependent NF- $\kappa$ B activation," Journal of Biological Chemistry, vol. 285, no. 32, pp. 24793-24804, 2010.

[125] P. Wang, F. Zhu, and K. Konstantopoulos, "Prostaglandin E2 induces interleukin-6 expression in human chondrocytes via cAMP/protein kinase A- and phosphatidylinositol 3kinase-dependent NF- $\kappa \mathrm{B}$ activation," American Journal of Physiology, vol. 298, no. 6, pp. 1445-1456, 2010.

[126] F. Zhu, P. Wang, N. H. Lee, M. B. Goldring, and K. Konstantopoulos, "Prolonged application of high fluid shear to chondrocytes recapitulates gene expression profiles associated with osteoarthritis," PLoS ONE, vol. 5, no. 12, Article ID e15174, 2010.

[127] P. M. Lin, C. T. C. Chen, and P. A. Torzilli, "Increased stromelysin-1 (MMP-3), proteoglycan degradation (3B3and 7D4) and collagen damage in cyclically load-injured articular cartilage," Osteoarthritis and Cartilage, vol. 12, no. 6, pp. 485-496, 2004.

[128] J. Steinmeyer and B. Ackermann, "The effect of continuously applied cyclic mechanical loading on the fibronectin metabolism of articular cartilage explants," Research in Experimental Medicine, vol. 198, no. 5, pp. 247-260, 1999.

[129] S. Madhavan, M. Anghelina, B. Rath-Deschner et al., "Biomechanical signals exert sustained attenuation of proinflammatory gene induction in articular chondrocytes," Osteoarthritis and Cartilage, vol. 14, no. 10, pp. 1023-1032, 2006.

[130] R. Gassner, M. J. Buckley, H. Georgescu et al., "Cyclic tensile stress exerts anti-inflammatory actions on chondrocytes by inhibiting inducible nitric oxide synthase," Journal of Immunology, vol. 163, pp. 2187-2192, 1999.

[131] Z. Xu, M. J. Buckley, C. H. Evans, and S. Agarwal, "Cyclic tensile strain acts as an antagonist of IL-1 beta actions in chondrocytes," Journal of Immunology, vol. 165, pp. 453-460, 2000.

[132] T. T. Chowdhury, D. L. Bader, and D. A. Lee, "Dynamic compression inhibits the synthesis of nitric oxide and PGE2 by IL$1 \beta$ stimulated chondrocytes cultured in agarose constructs," Biochemical and Biophysical Research Communications, vol. 285, pp. 1168-1174, 2001.

[133] T. T. Chowdhury, S. Arghandawi, J. Brand et al., "Dynamic compression counteracts IL- $1 \beta$ induced inducible nitric oxide synthase and cyclo-oxygenase-2 expression in chondrocyte/agarose constructs," Arthritis Research and Therapy, vol. 10, no. 2, article no. R35, 2008.

[134] O. O. Akanji, P. Sakthithasan, D. M. Salter, and T. T. Chowdhury, "Dynamic compression alters NFkappaB activation and IkappaB-alpha expression in IL-1beta-stimulated chondrocyte/agarose constructs," Inflammation Research, vol. 59, no. 1, pp. 41-52, 2010.

[135] S. Agarwal, J. Deschner, P. Long et al., "Role of NFkappaB transcription factors in anti-inflammatory and proinflammatory actions of mechanical signals," Arthritis and Rheumatism, vol. 50, pp. 3541-3548, 2004.

[136] S. J. Millward-Sadler, M. O. Wright, H. S. Lee et al., "Integrinregulated secretion of interleukin 4: a novel pathway of mechanotransduction in human articular chondrocytes," Journal of Cell Biology, vol. 145, no. 1, pp. 183-189, 1999.

[137] S. J. Millward-Sadler, N. S. Khan, M. G. Bracher, M. O. Wright, and D. M. Salter, "Roles for the interleukin4 receptor and associated JAK/STAT proteins in human articular chondrocyte mechanotransduction," Osteoarthritis and Cartilage, vol. 14, no. 10, pp. 991-1001, 2006.

[138] D. M. Salter, S. J. Millward-Sadler, G. Nuki, and M. O. Wright, "Integrin-interleukin-4 mechanotransduction pathways in human chondrocytes," Clinical Orthopaedics and Related Research, no. 391, pp. S49-S60, 2001.

[139] T. T. Chowdhury, D. M. Salter, D. L. Bader, and D. A. Lee, "Integrin-mediated mechanotransduction processes in TGF $\beta$-stimulated monolayer-expanded chondrocytes," Biochemical and Biophysical Research Communications, vol. 318, no. 4, pp. 873-881, 2004.

[140] T. T. Chowdhury, R. N. Appleby, D. M. Salter, D. A. Bader, and D. A. Lee, "Integrin-mediated mechanotransduction in IL-1 $\beta$ stimulated chondrocytes," Biomechanics and Modeling in Mechanobiology, vol. 5, no. 2-3, pp. 192-201, 2006.

[141] M. O. Wright, K. Nishida, C. Bavington et al., "Hyperpolarisation of cultured human chondrocytes following cyclical pressure-induced strain: evidence of a role for $\alpha 5 \beta 1$ integrin as a chondrocyte mechanoreceptor," Journal of Orthopaedic Research, vol. 15, no. 5, pp. 742-747, 1997.

[142] H. S. Lee, S. J. Millward-Sadler, M. O. Wright, G. Nuki, and D. M. Salter, "Integrin and mechanosensitive ion channel-dependent tyrosine phosphorylation of focal adhesion proteins and $\beta$-catenin in human articular chondrocytes after mechanical stimulation," Journal of Bone and Mineral Research, vol. 15, no. 8, pp. 1501-1509, 2000.

[143] M. M. Knight, T. Toyoda, D. A. Lee, and D. L. Bader, "Mechanical compression and hydrostatic pressure induce reversible changes in actin cytoskeletal organisation in chondrocytes in agarose," Journal of Biomechanics, vol. 39, no. 8, pp. 1547-1551, 2006.

[144] T. T. Chowdhury, D. L. Bader, and D. A. Lee, "Antiinflammatory effects of IL-4 and dynamic compression in IL- $1 \beta$ stimulated chondrocytes," Biochemical and Biophysical Research Communications, vol. 339, no. 1, pp. 241-247, 2006.

[145] H. Doi, K. Nishida, M. Yorimitsu et al., "Interleukin4 downregulates the cyclic tensile stress-induced matrix metalloproteinases-13 and cathepsin $\mathrm{b}$ expression by rat normal chondrocytes," Acta Medica Okayama, vol. 62, no. 2, article 7, pp. 119-126, 2008.

[146] T. Vincent, M. Hermansson, M. Bolton, R. Wait, and J. Saklatvala, "Basic FGF mediates an immediate response of articular cartilage to mechanical injury," Proceedings of the National Academy of Sciences of the United States of America, vol. 99, no. 12, pp. 8259-8264, 2002. 
[147] T. L. Vincent, C. J. McLean, L. E. Full, D. Peston, and J. Saklatvala, "FGF-2 is bound to perlecan in the pericellular matrix of articular cartilage, where it acts as a chondrocyte mechanotransducer," Osteoarthritis and Cartilage, vol. 15, no. 7, pp. 752-763, 2007.

[148] M. O. Wright, K. Nishida, C. Bavington et al., "Hyperpolarisation of cultured human chondrocytes following cyclical pressure-induced strain: evidence of a role for alpha 5 beta 1 integrin as a chondrocyte mechanoreceptor," Journal of Orthopaedic Research, vol. 15, no. 5, pp. 742-747, 1997.

[149] W. B. Valhmu and F. J. Raia, "myo-inositol 1,4,5trisphosphate and $\mathrm{Ca} 2+/$ calmodulin-dependent factors mediate transduction of compression-induced signals in bovine articular chondrocytes," Biochemical Journal, vol. 361, part 3, pp. 689-696, 2002.

[150] Y. Geng and M. Lotz, "Increased intracellular Ca2+ selectively suppresses IL-1-induced NO production by reducing iNOS mRNA stability," Journal of Cell Biology, vol. 129, no. 6, pp. 1651-1657, 1995.

[151] S. J. Millward-Sadler, M. O. Wright, P. W. Flatman, and D. M. Salter, "ATP in the mechanotransduction pathway of normal human chondrocytes," Biorheology, vol. 41, no. 3-4, pp. 567$575,2004$.

[152] T. T. Chowdhury and M. M. Knight, "Purinergic pathway suppresses the release of NO and stimulates proteoglycan synthesis in chondrocyte/agarose constructs subjected to dynamic compression," Journal of Cellular Physiology, vol. 209, no. 3, pp. 845-853, 2006.

[153] H. Yokota, M. B. Goldring, and H. B. Sun, "CITED2mediated regulation of MMP-1 and MMP-13 in human chondrocytes under flow shear," Journal of Biological Chemistry, vol. 278, no. 47, pp. 47275-47280, 2003.

[154] D. J. Leong, Y. H. Li, X. I. Gu et al., "Physiological loading of joints prevents cartilage degradation through CITED2," FASEB Journal, vol. 25, no. 1, pp. 182-191, 2011.

[155] N. Gerwin, C. Hops, and A. Lucke, "Intraarticular drug delivery in osteoarthritis," Advanced Drug Delivery Reviews, vol. 58, no. 2, pp. 226-242, 2006.

[156] J. P. Caron, J. C. Fernandes, J. Martel-Pelletier et al., "Chondroprotective effect of intraarticular injections of interleukin-1 receptor antagonist in experimental osteoarthritis: suppression of collagenase-1 expression," Arthritis and Rheumatism, vol. 39, no. 9, pp. 1535-1544, 1996.

[157] M. Yorimitsu, K. Nishida, A. Shimizu et al., "Intra-articular injection of interleukin-4 decreases nitric oxide production by chondrocytes and ameliorates subsequent destruction of cartilage in instability-induced osteoarthritis in rat knee joints," Osteoarthritis and Cartilage, vol. 16, no. 7, pp. 764771, 2008.

[158] M. Jin, G. R. Emkey, P. Siparsky, S. B. Trippel, and A. J. Grodzinsky, "Combined effects of dynamic tissue shear deformation and insulin-like growth factor I on chondrocyte biosynthesis in cartilage explants," Archives of Biochemistry and Biophysics, vol. 414, no. 2, pp. 223-231, 2003.

[159] E. G. Lima, L. Bian, K. W. Ng et al., "The beneficial effect of delayed compressive loading on tissue-engineered cartilage constructs cultured with TGF- $\beta 3$," Osteoarthritis and Cartilage, vol. 15, no. 9, pp. 1025-1033, 2007.

[160] I. C. Helmark, U. R. Mikkelsen, J. Borglum et al., "Exercise increases interleukin-10 levels both intraarticularly and perisynovially in patients with knee osteoarthritis: a randomized controlled trial," Arthritis Research and Therapy, p. R126, 2010.
[161] M. Anghelina, D. Sjostrom, P. Perera, J. Nam, T. Knobloch, and S. Agarwal, "Regulation of biomechanical signals by NF$\kappa \mathrm{B}$ transcription factors in chondrocytes," Biorheology, vol. 45, no. 3-4, pp. 245-256, 2008.

[162] P. M. Perera, E. Wypasek, S. Madhavan et al., "Mechanical signals control Sox-9, Vegf and c-Myc expression and cell proliferation during inflammation via integrin-linked kinase, B-Raf, and ERK 1/2-dependent signaling in articular chondrocytes," Arthritis Research and Therapy, vol. 12, no. 3, p. R106, 2010.

[163] F. Bao, Y. Chen, K. A. Schneider, and L. C. Weaver, "An integrin inhibiting molecule decreases oxidative damage and improves neurological function after spinal cord injury," Experimental Neurology, vol. 214, no. 2, pp. 160-167, 2008.

[164] D. M. Salter, M. O. Wright, and S. J. Millward-Sadler, "NMDA receptor expression and roles in human articular chondrocyte mechanotransduction," Biorheology, vol. 41, no. 3-4, pp. 273-281, 2004.

[165] L. Ramage, M. A. Martel, G. E. Hardingham, and D. M. Salter, "NMDA receptor expression and activity in osteoarthritic human articular chondrocytes," Osteoarthritis and Cartilage, vol. 16, no. 12, pp. 1576-1584, 2008.

[166] S. R. McGlashan, E. C. Cluett, C. G. Jensen, and C. A. Poole, "Primary Cilia in osteoarthritic chondrocytes: from chondrons to clusters," Developmental Dynamics, vol. 237, no. 8, pp. 2013-2020, 2008.

[167] M. Garcia and M. M. Knight, "Cyclic loading opens hemichannels to release ATP as part of a chondrocyte mechanotransduction pathway," Journal of Orthopaedic Research, vol. 28, no. 4, pp. 510-515, 2010.

[168] Y. Xing, Y. Gu, R. R. Gomes Jr., and J. You, "P2Y(2) receptors and GRK2 are involved in oscillatory fluid flow induced ERK1/2 responses in chondrocytes," Journal of Orthopaedic Research, vol. 29, no. 6, pp. 828-833, 2011.

[169] D. M. Salter, S. J. Millward-Sadler, G. Nuki, and M. O. Wright, "Differential responses of chondrocytes from normal and osteoarthritic human articular cartilage to mechanical stimulation," Biorheology, vol. 39, no. 1-2, pp. 97-108, 2002.

[170] S. J. Millward-Sadler, M. O. Wright, H. S. Lee, H. Caldwell, G. Nuki, and D. M. Salter, "Altered electrophysiological responses to mechanical stimulation and abnormal signalling through $\alpha 5 \beta 1$ integrin in chondrocytes from osteoarthritic cartilage," Osteoarthritis and Cartilage, vol. 8, no. 4, pp. 272278, 2000. 


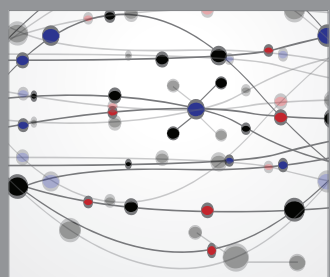

The Scientific World Journal
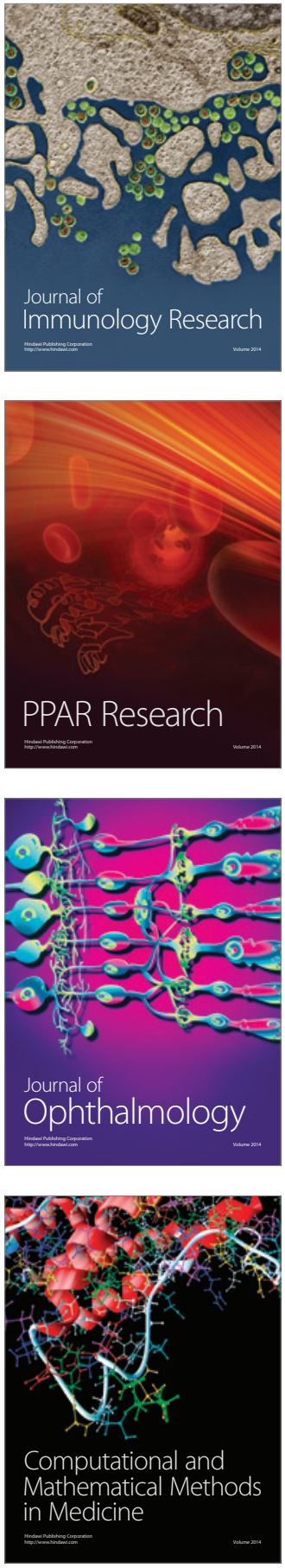

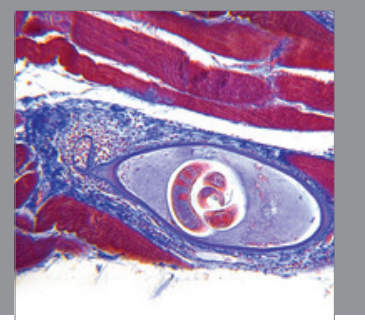

Gastroenterology

Research and Practice
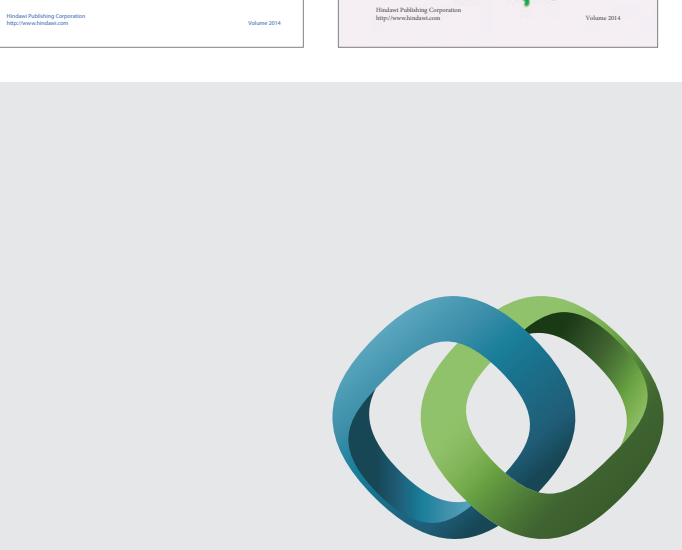

\section{Hindawi}

Submit your manuscripts at

http://www.hindawi.com
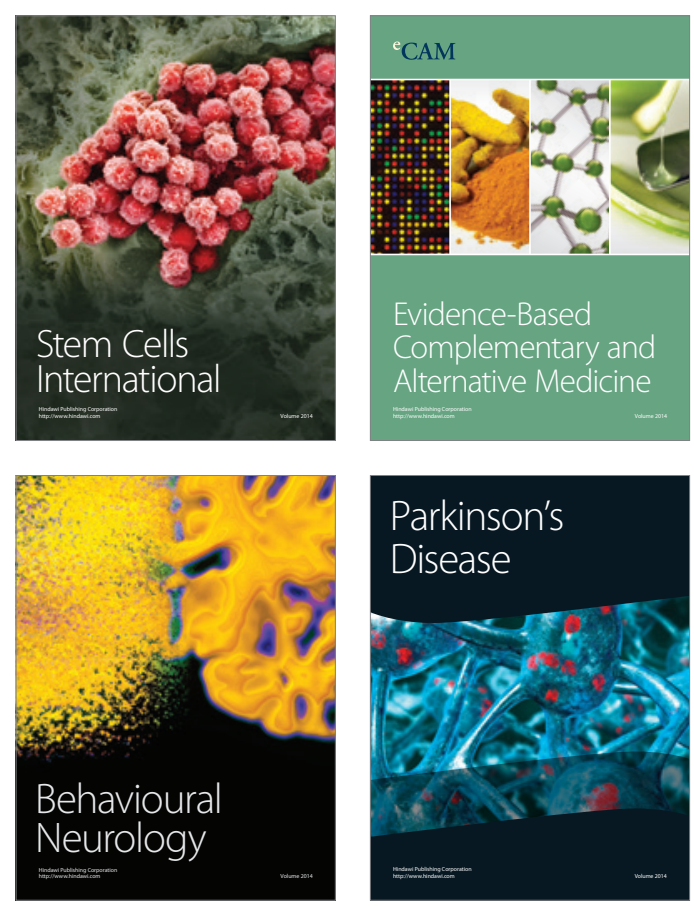

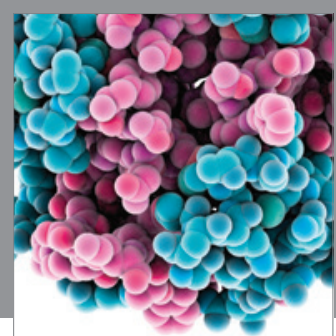

Journal of
Diabetes Research

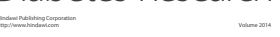

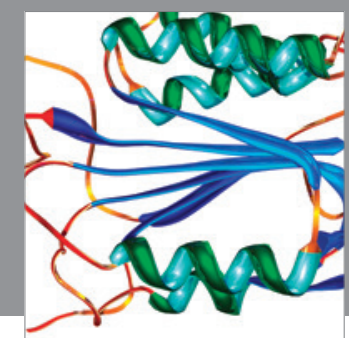

Disease Markers
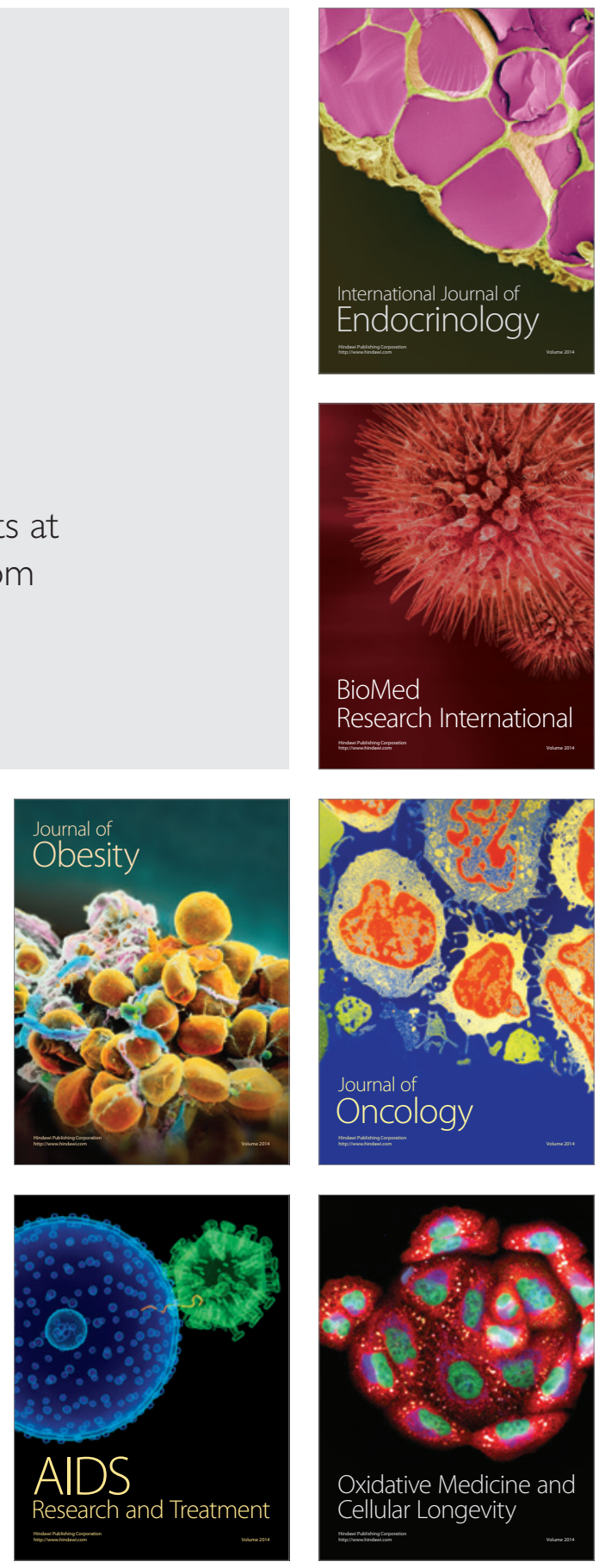